\title{
Intracranial Atherosclerotic Stenoses: Pathophysiology, Epidemiology, Risk Factors and Current Therapy Options
}

\author{
Marina Petrova Krasteva - Kui Kai Lau - Pasquale Mordasini · \\ Anderson Chun On Tsang · Mirjam Rachel Heldner
}

Received: January 23, 2020 / Published online: April 8, 2020

(C) The Author(s) 2020

\begin{abstract}
Intracranial atherosclerotic stenoses (ICAS) are one of the most common causes of first and recurrent cerebrovascular ischaemic events worldwide, with highest prevalence in Asian, Hispanic and African populations. Clinical trials have improved the understanding of epidemiology, risk factors and imaging characteristics of
\end{abstract}

Enhanced Digital Features To view digital features for this article go to https://doi.org/10.6084/m9.figshare. 11950599.

M. P. Krasteva · M. R. Heldner ( $\square)$

Department of Neurology, Inselspital, University Hospital and University of Bern, Bern, Switzerland e-mail: mirjam.heldner@insel.ch

P. Mordasini

Institute of Diagnostic and Interventional

Neuroradiology, Inselspital, University Hospital and University of Bern, Bern, Switzerland

K. K. Lau

Division of Neurology, Department of Medicine, Queen Mary Hospital, The University of Hong Kong, Pokfulam, Hong Kong

A. C. O. Tsang

Division of Neurosurgery, Department of Surgery, Queen Mary Hospital, The University of Hong Kong, Pokfulam, Hong Kong patients with ICAS. Current therapeutic approaches concerning these patients include management of risk factors, best medical therapy, potentially endovascular and rarely surgical therapy. In our review, we elucidate the current epidemiology and evidence in evaluation of risk factors and therapeutic options for providing favourable outcome for patients with ICAS.

\section{PLAIN LANGUAGE SUMMARY}

Calcified vessels in the brain are one of the most common causes of first or recurrent ischaemic stroke or transient ischaemic attack worldwide, with highest occurrence in Asian, Hispanic and African populations. Clinical trials have improved the understanding of this particular disease. Current therapy includes management of risk factors, best medical therapy, potentially therapy with a wire and rarely surgical therapy. In our review, we elucidate current knowledge and recommendations.

Keywords: Intracranial atherosclerotic stenosis; Best medical therapy; Endovascular therapy; Surgical therapy 


\section{Key Summary Points}

Intracranial atherosclerotic stenoses are one of the most common causes of first and recurrent cerebrovascular ischaemic events worldwide

Artery-to-artery embolism, obstruction of small penetrating arteries and impaired washout of emboli in hypoperfused cerebral tissue with/without poor collaterals are the most important cerebrovascular event mechanisms in these patients

Current therapeutic approaches in these patients include management of risk factors, best medical therapy, potentially endovascular and rarely surgical therapy

Novel, large-scale and high-power randomised clinical trials investigating efficacy and safety of best medical therapy including modern treatment such as proprotein convertase subtilisin/kexin type 9 (PSCK9) inhibitors and endovascular therapy are urgently needed in these patients

Careful patient selection for endovascular therapy, related to the underlying pathophysiological mechanism of cerebrovascular ischaemic events, as well as improved endovascular devices could result in future better outcome

\section{INTRODUCTION}

Intracranial atherosclerotic stenoses (ICAS) are one of the most common causes of cerebrovascular ischaemic events worldwide. ICAS account for around half of transient ischaemic attacks (TIAs) and ischaemic strokes in Asian populations, for up to one-third in Black populations,
$15 \%$ in Hispanic populations and $5-10 \%$ in Caucasian populations [1-4]. The annual risk of recurrent cerebrovascular ischaemic events in patients with ICAS varies from $4 \%$ to $40 \%$ according to different studies [5-9]. Risk factors for ICAS traditionally include arterial hypertension, diabetes mellitus, dyslipidaemia, overweight, physical inactivity and smoking. Age and ethnicity also seem to play an important role $[2,10]$.

Despite considerable rates of patients with ICAS, there are still controversies as to what extent best medical therapy improves outcome and decreases rates of recurrent cerebrovascular ischaemic events, disability and mortality and which patients might benefit from endovascular or from surgical therapy. Of note, ICAS is a heterogeneous disease, causing cerebrovascular ischaemic events by several pathophysiological mechanisms [11].

We aimed to present a comprehensive overview on pathophysiology, epidemiology, risk factors and current therapy options of patients with ICAS by performing a systemic review of current available data.

\section{METHOD}

\section{Eligibility Criteria}

Eligible studies included all age and ethnic patient groups with demographic, clinical, laboratory and imaging information on patients with asymptomatic or symptomatic ICAS. We excluded studies on patients with nonatherosclerotic intracranial stenoses and patients with extracranial atherosclerotic stenoses (ECAS) only, as well as case reports and case series with less than five patients.

\section{Information Sources}

Data for this review was identified via a search on MEDLINE, PubMed and Scopus. Relevant articles were determined using the search terms "ICAS", OR "intracranial atherosclerotic 
stenosis" OR "intracranial stenosis" AND/OR "ischaemic stroke" OR "TIA" OR "transient ischaemic attack". Articles published in English and German between 1 January 1985 and 31 December 2019 were included.

\section{Study Selection}

Citations were assessed against the predetermined inclusion and exclusion criteria by MPK and MRH. Full-text manuscripts were obtained for all studies entering the review. Any uncertainties about including a specific manuscript were resolved by consensus. Reasons for exclusion of publications were mainly lack of specific data e.g. on precise location of atherosclerosis. Finally, several randomised, observational, nonrandomised controlled trials regarding patients with ICAS met the inclusion criteria and are elucidated in this review.

\section{Compliance with Ethics Guidelines}

This article is based on previously conducted studies and does not contain any studies performed by any of the authors with human participants or animals.

\section{DIAGNOSTIC EVALUATION}

Diagnostic evaluation of ICAS include transcranial Doppler (TCD) and colour-coded duplex (TCCD) sonography, magnetic resonance angiography (MRA), computed tomography angiography (CTA) and digital subtraction angiography (DSA). Although TCD, TCCD, MRA and CTA are non-invasive, safer and easier accessible modalities, DSA is still considered to be the gold standard technique for assessing ICAS [12].

Since neuroimaging techniques have become more and more available and advanced, several studies related to ICAS have been published within recent years. However, there are still far more studies published in the field of ECAS [13-15].

\section{PATHOPHYSIOLOGY \\ OF CEREBROVASCULAR ISCHAEMIC EVENTS RELATED TO INTRACRANIAL ATHEROSCLEROTIC STENOSIS}

Modern neuroimaging techniques such as diffusion-weighted MR imaging (MRI), perfusionweighted CT/MRI, MRA, CTA and high-resolution vessel wall MRI have provided new insights into ICAS and into their mechanisms causing cerebrovascular ischaemic events.

An autopsy study $(n=339$ brains with ischaemic brain infarcts, $n=80$ controls with intracerebral haemorrhages) showed ischaemic stroke to be associated with greater than 30\% ICAS in $27 \%$ vs. less than $30 \%$ ICAS in $15.5 \%$ $(p<0.05)$. In those where the stenotic plaques were considered to be the cause of ischaemic stroke ( $n=15 / 259,5.8 \%)$, because of superimposed clot or ulcerated plaques, higher-grade ICAS was more prevalent $(73 \%$ vs. $27 \%$; $p<0.0001$, in greater than $75 \%$ vs. $30-75 \%$ ICAS) [16]. Also, other studies have shown a correlation of higher-grade ICAS and cerebrovascular ischaemic events $[7,17,18]$.

Artery-to-artery embolism, obstruction of small penetrating arteries and impaired washout of emboli in hypoperfused cerebral tissue with/without poor collaterals are the most important cerebrovascular event mechanisms in patients with ICAS. Rarer causes are hypoperfusion with/without poor collaterals as such or local vessel occlusion. Recent advances in neuroimaging technologies allow one to determine the underlying pathophysiological mechanism.

Artery-to-artery embolism is caused by a thrombus carried to the distal territory by rupture of the atherosclerotic plaque causing ICAS with/without an additional thrombus. Turbulence of blood flow caused by the vessel narrowing, as well as fast velocity increase and shear stress on the endothelium encourage fissuring of the plaque. The latter may rupture and may lead to activation of platelets and clotting factors. In the case of an ischaemic stroke caused by this mechanism, typically, multiple, 
scattered, small infarcts are seen on diffusionweighted MRI (DWI) [19].

Obstruction of small penetrating arteries (Fig. 1) is caused by atherosclerotic plaques protruding into the orifice of perforators and thus impairing blood flow. If an ischaemic stroke is caused by this mechanism, typically, deep subcortical infarcts are seen on DWI [20].

Intracranial atherosclerotic plaques can be identified by high-resolution (HR) vessel wall MRI and by intravascular sonography, which allow visualization not only of the vessel lumen but also of the vessel wall. Similar to more accessible extracranial plaques, intracranial plaques with thin fibrous caps, large lipid cores, high macrophage content, high microvessel density and intraplaque haemorrhage are considered to be unstable and rupture prone due to the increased risk of plaque destabilization [21-30].

Hypoperfusion with/without poor collaterals may be present in high-grade ICAS. Its typical infarction shows a border zone location and pattern [31].

In situ obstruction may possibly show moderate to even large infarcts, especially if the intracranial internal carotid artery, proximal middle cerebral artery or vertebrobasilar arteries are involved leading to an acute large vessel occlusion. However, compared to patients with cardiac embolism, infarct size is smaller in many patients with ICAS because of the welldeveloped collateral circulation due to the chronic nature of the disease [19].

Of note, a combination of more than one mechanism is also possible [32-34]. For example, impaired washout of emboli may occur in the case of embolism and hypoperfusion with/ without poor collaterals combined [35].

In the WASID (Warfarin-Aspirin Symptomatic Intracranial Disease) trial (Table 1), not all 70-99\% ICAS were haemodynamically relevant and not all 50-69\% ICAS were haemodynamically irrelevant. Collaterals may be seen in present or regressed high-grade ICAS. Depending on the overall haemodynamic status, collaterals may develop in moderate ICAS as well. Furthermore, collaterals may indicate the presence of an emboligenic plaque, with past emboli having induced collateral flow. Also, competing antegrade vs. retrograde collateral flow may cause slower flow at the ICAS location rendering it more thrombogenic [17].

\section{ASYMPTOMATIC INTRACRANIAL ATHEROSCLEROTIC STENOSES}

Few studies have specifically investigated the prevalence, risk factors and prognosis of asymptomatic ICAS, such as the AsIA (Barcelona Asymptomatic Intracranial Atherosclerosis) and the Rotterdam study (Table 1) [36, 37].

A post hoc analysis of data from the WASID trial showed coexisting asymptomatic ICAS in $18.9 \%(n=14 / 74)$ of patients who underwent DSA and in $27.3 \%(n=65 / 238)$ who underwent MRA. During follow-up, despite the high rate of coexisting symptomatic ICAS, the risk of recurrent ischaemic stroke due to asymptomatic ICAS was low and only 5 (5.9\%, 95\% CI 2.1-12.3\%) ischaemic strokes occurred in the asymptomatic ICAS territory (risk at 1 year $3.5 \%, 95 \%$ CI $0.8-9.0 \%$ ) [40].
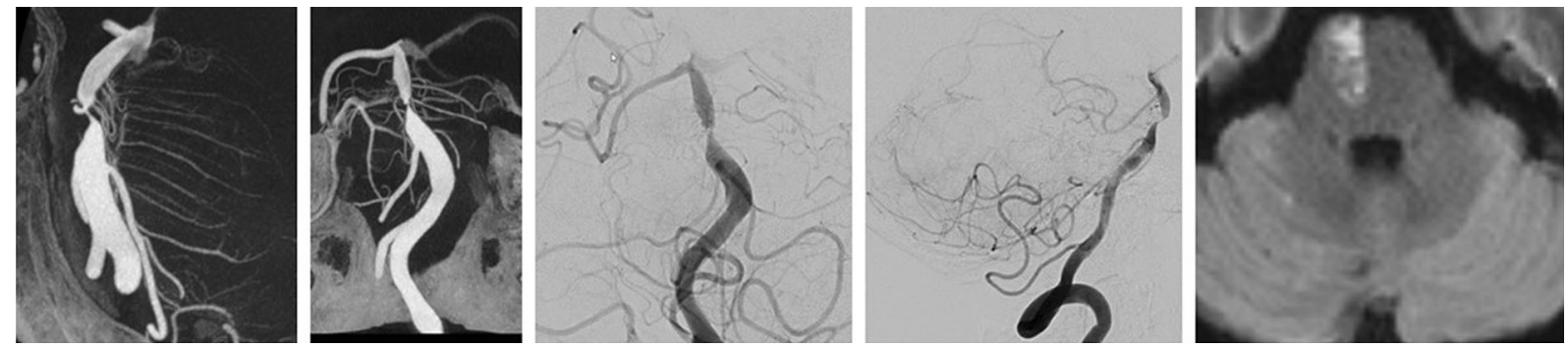

Fig. 1 High-resolution flat panel cone beam CT, DSA and MRI of a patient with high-grade ICAS of the basilar artery and ischaemic stroke predominantly of a perforator-type pattern 


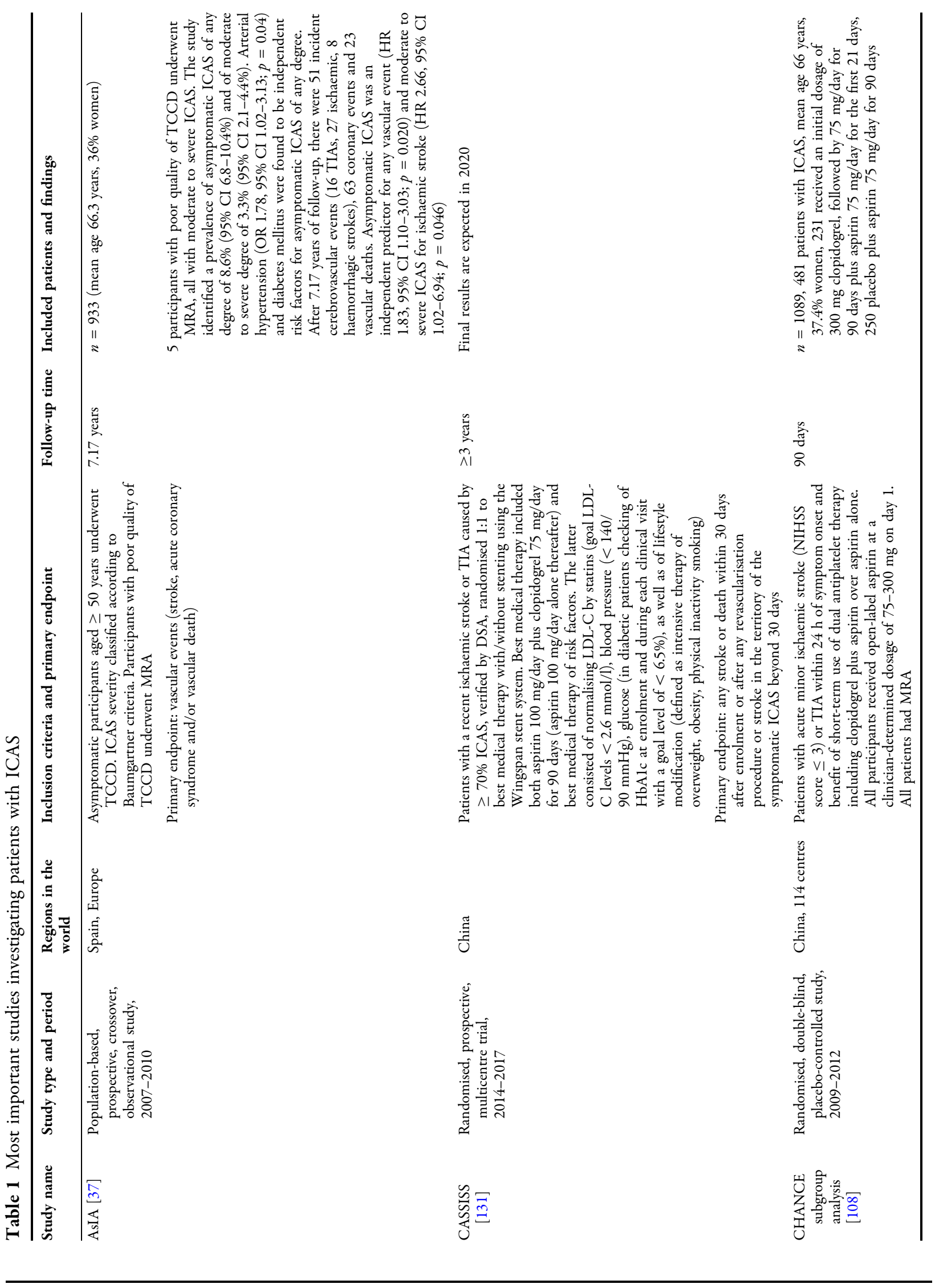




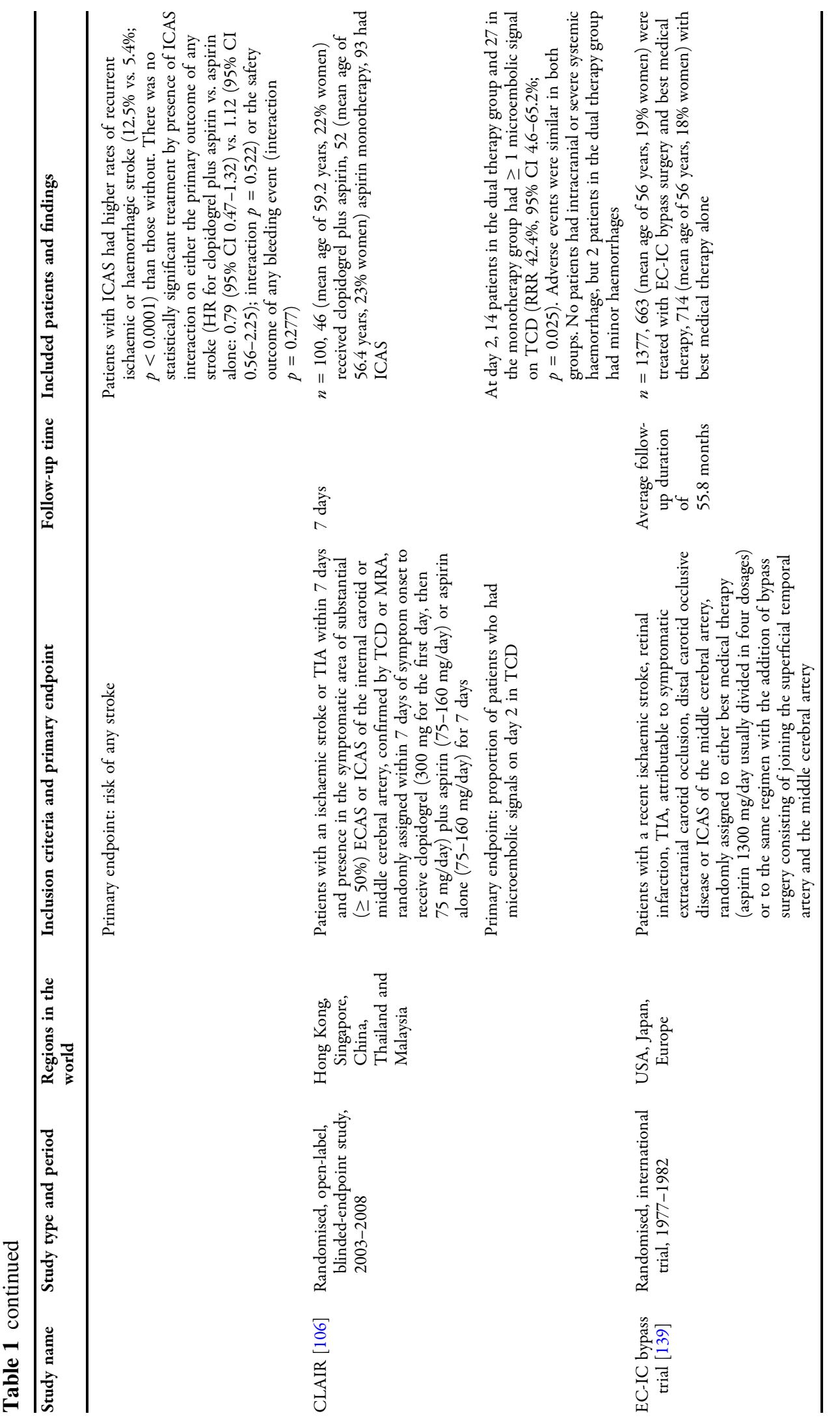




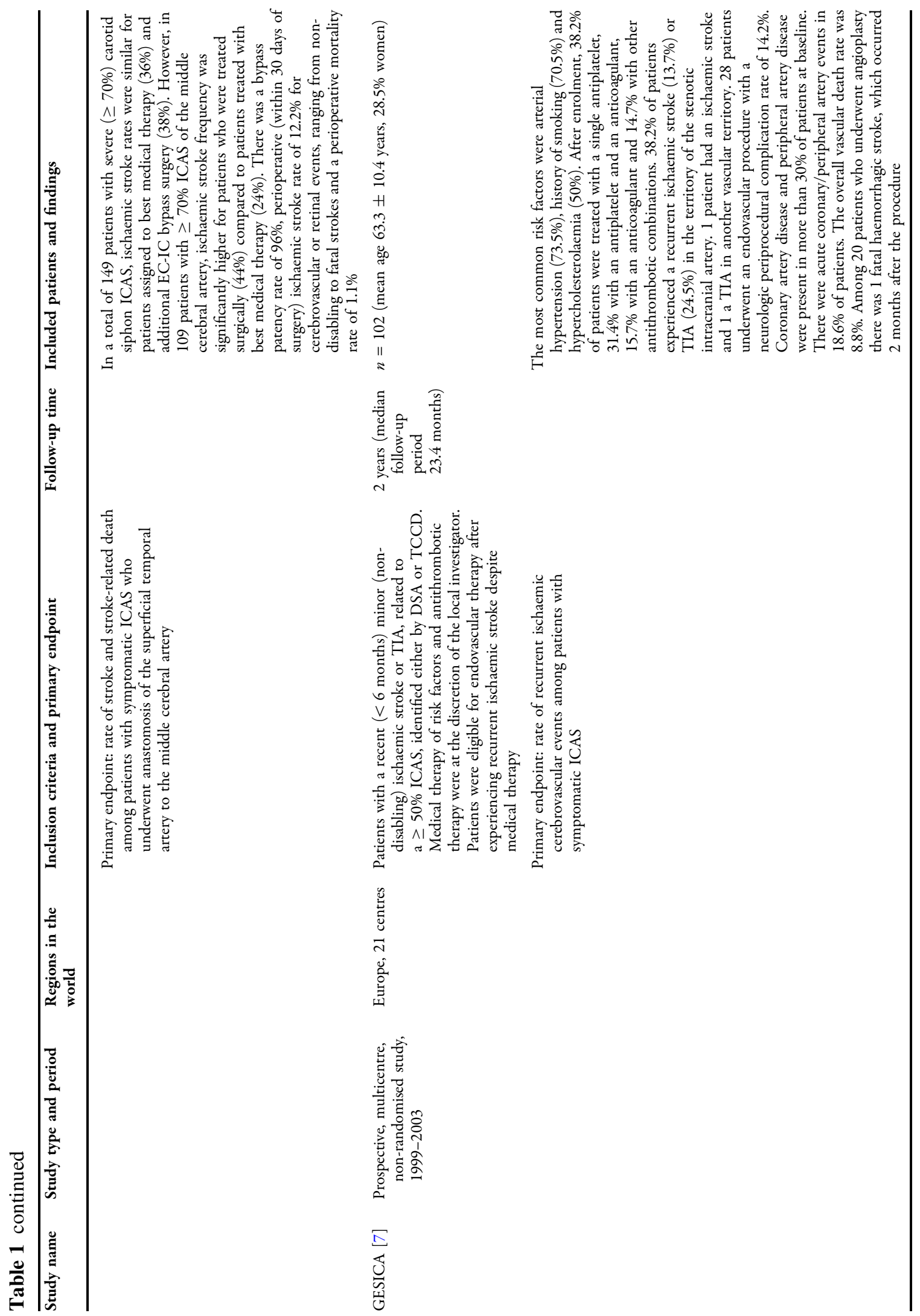




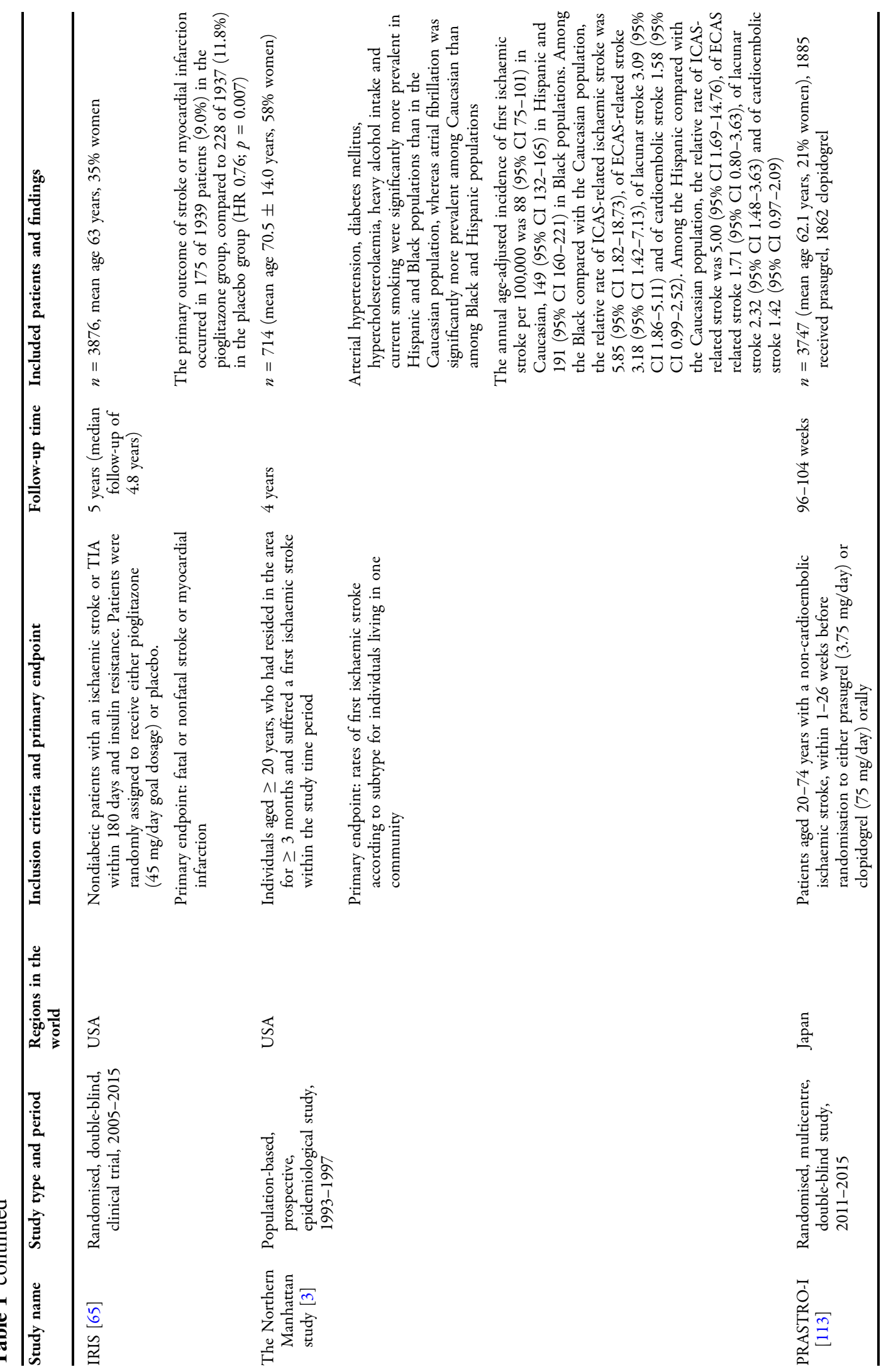




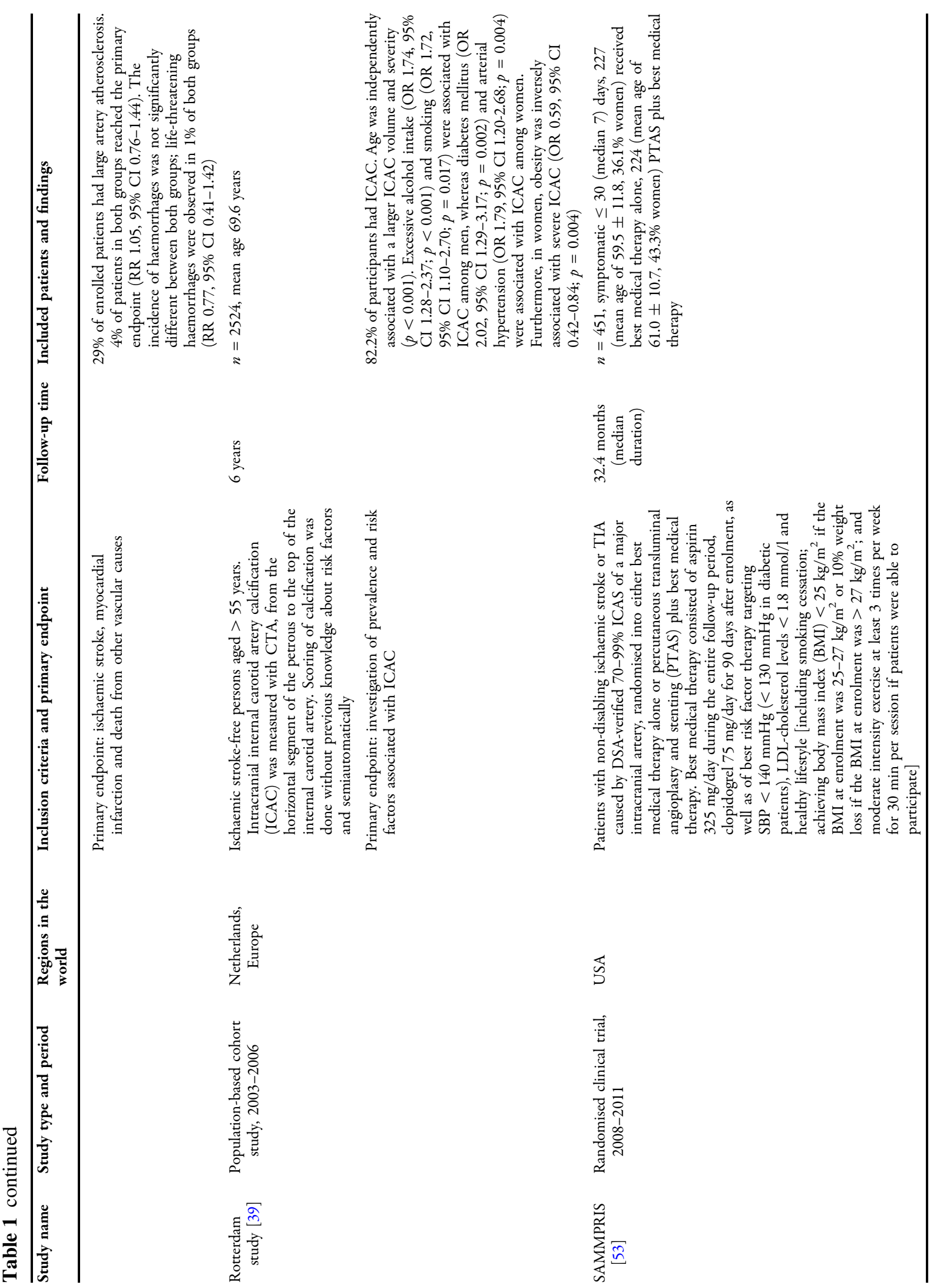




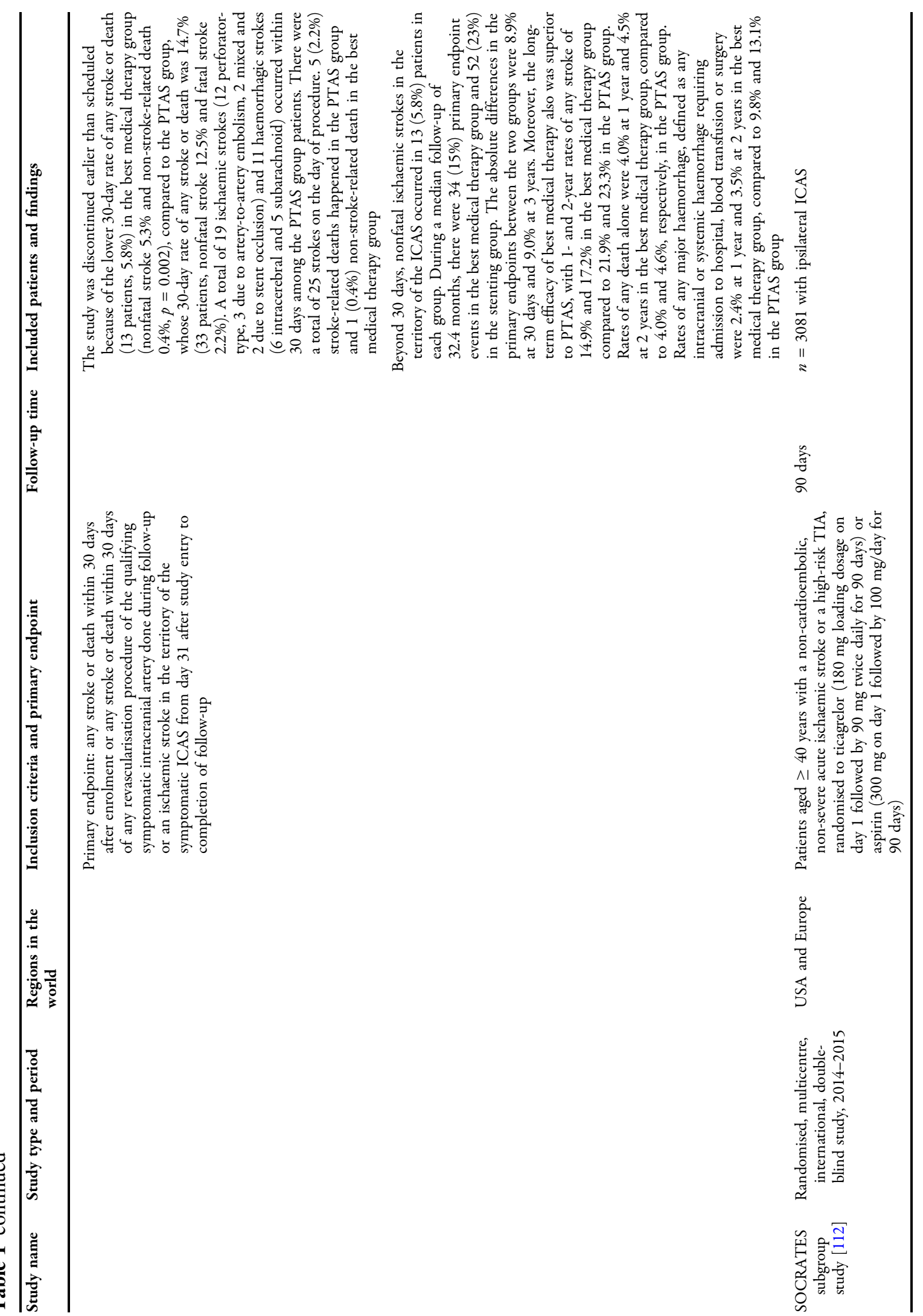




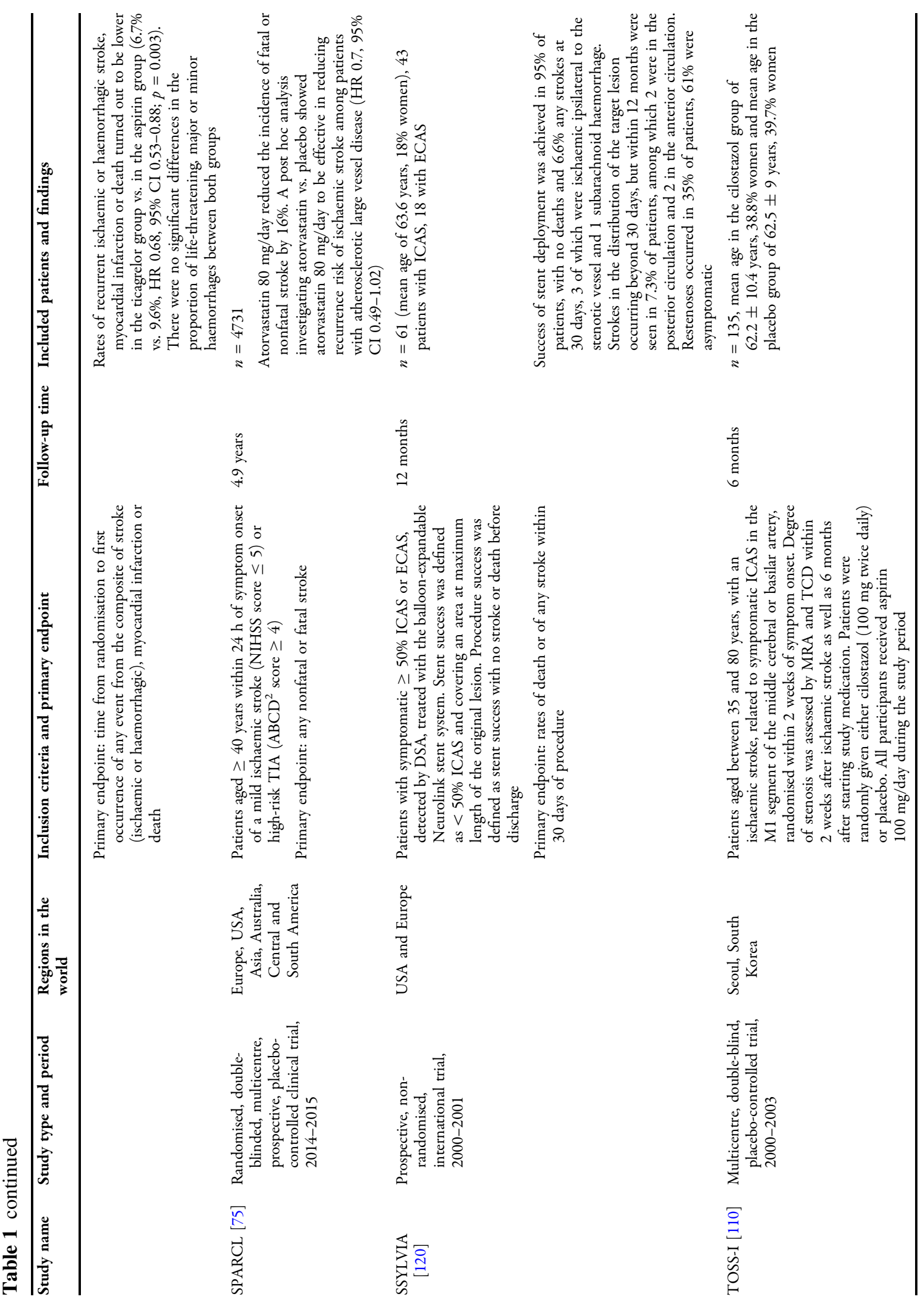




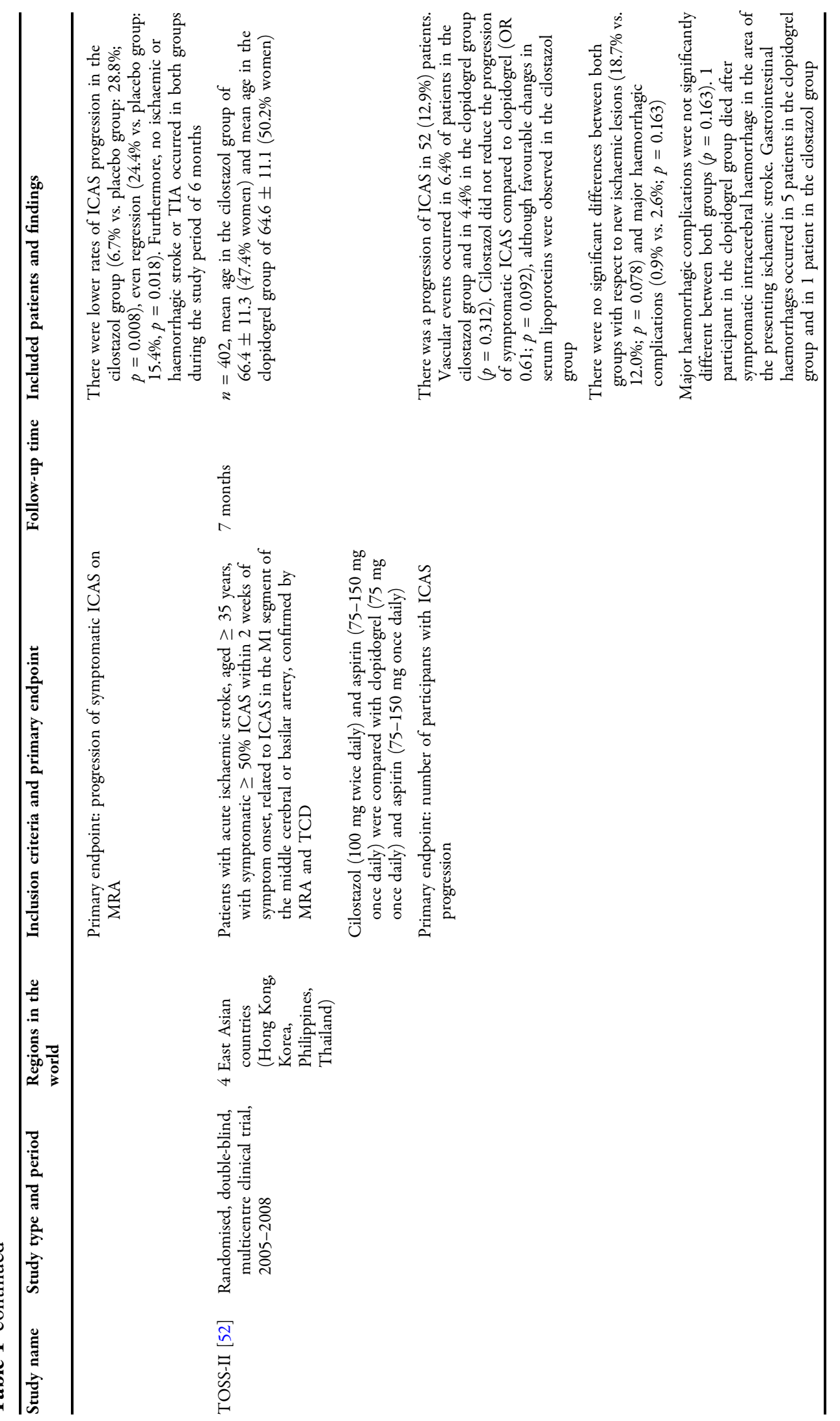




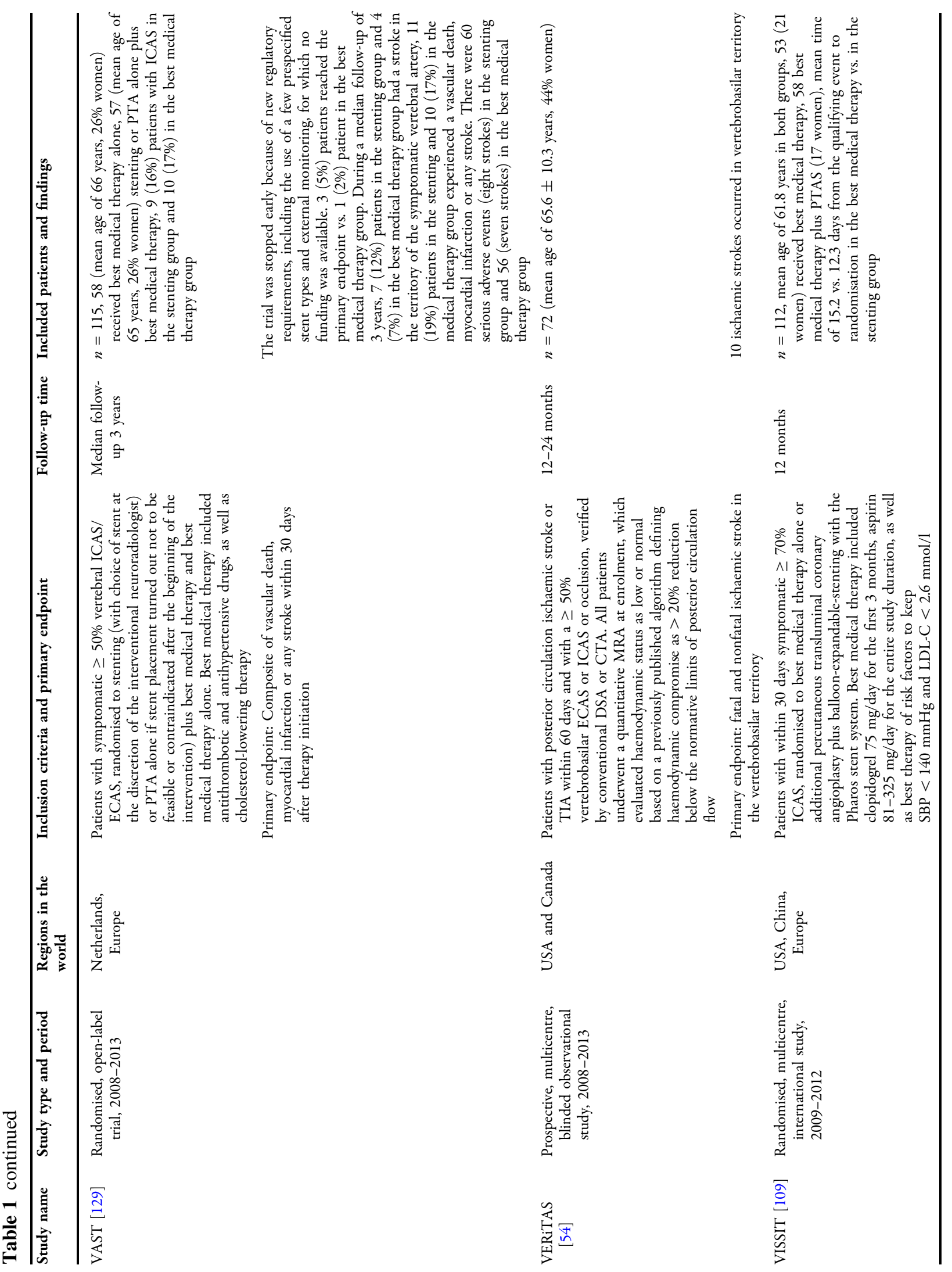




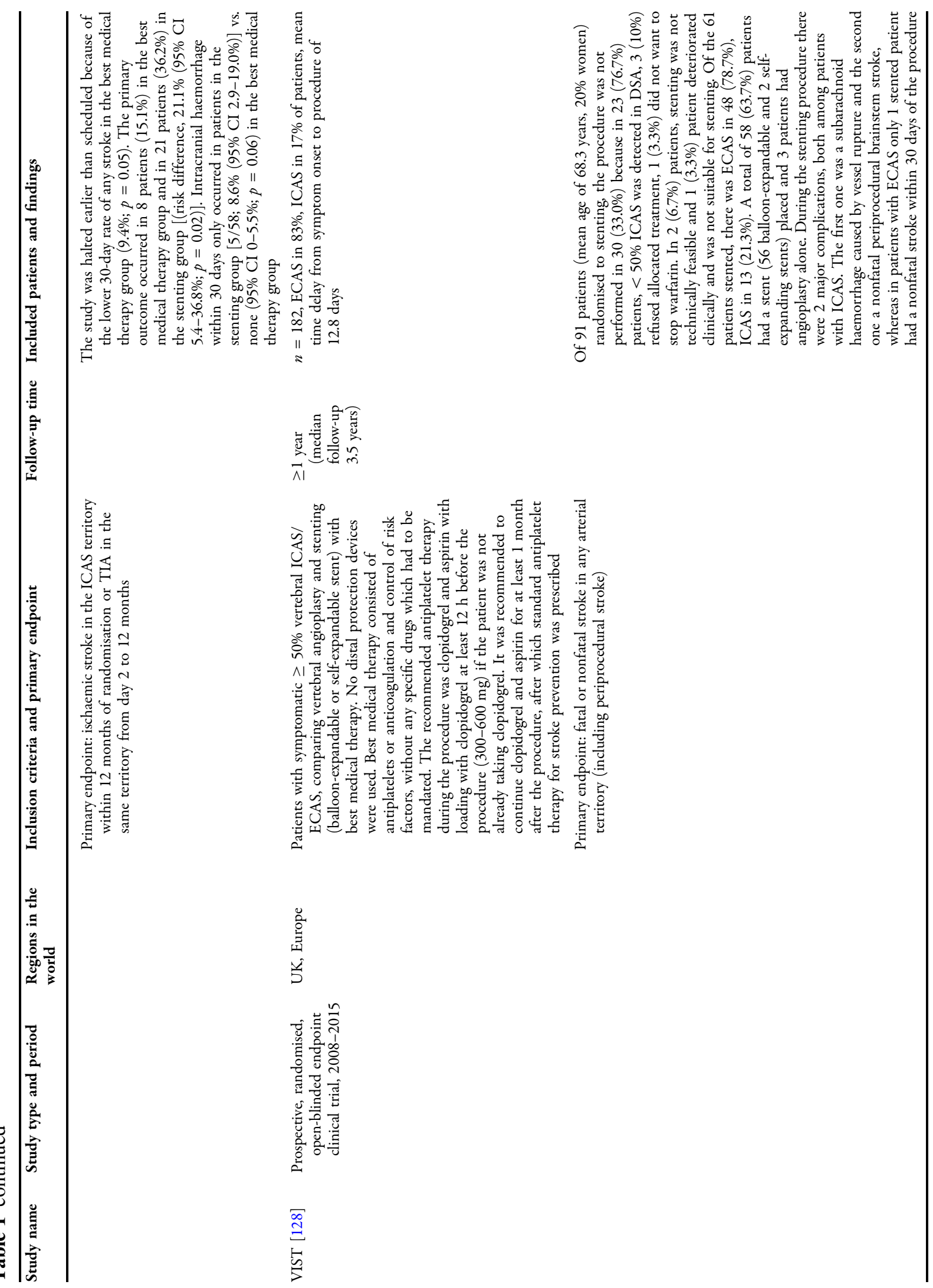




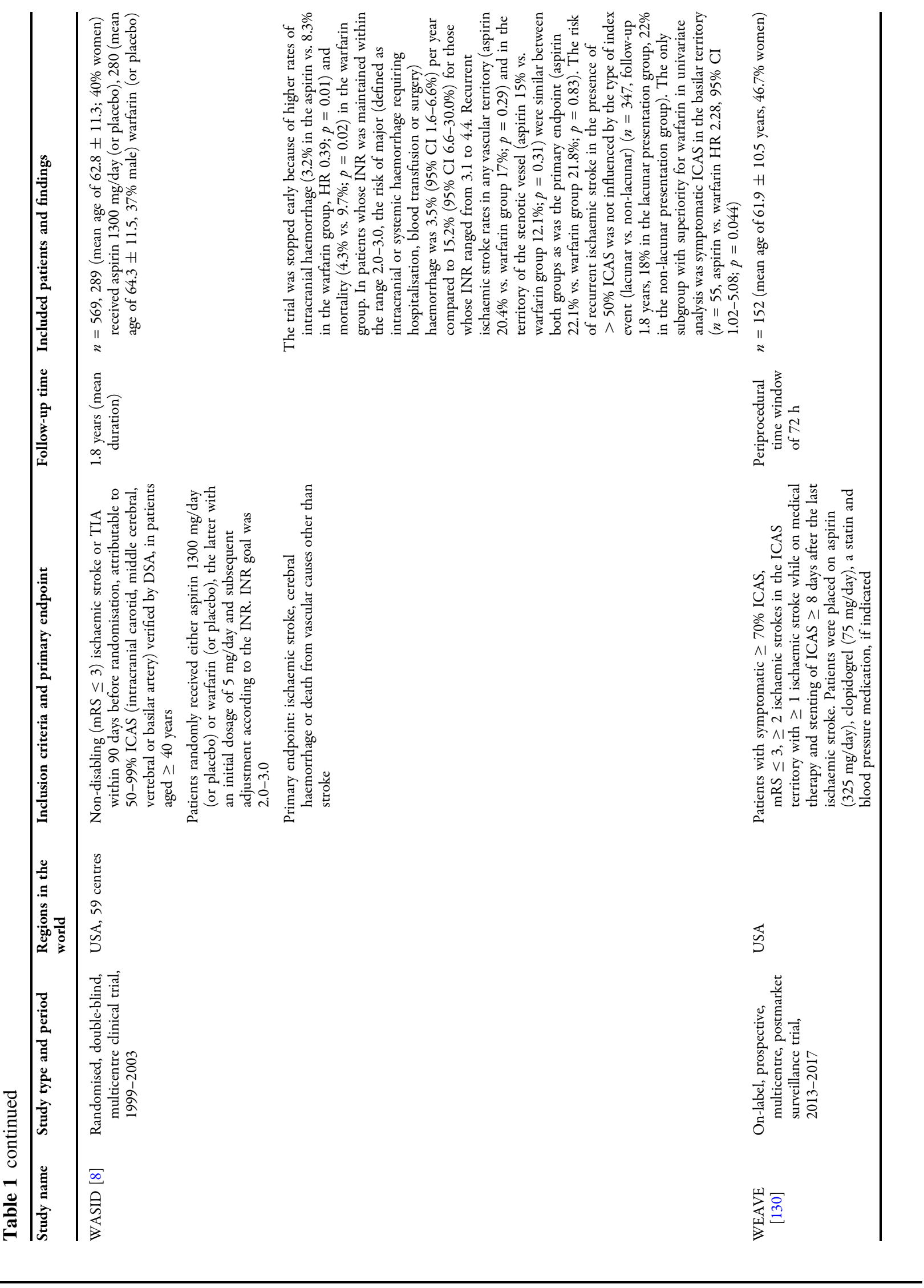




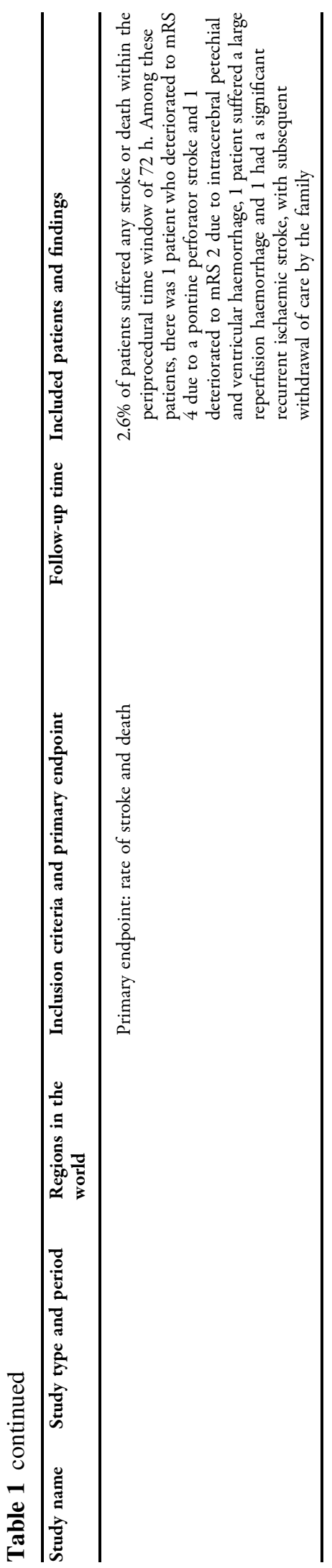

Despite the reported prevalence and impact of asymptomatic ICAS, the focus of our review is on symptomatic ICAS.

\section{EPIDEMIOLOGY, RISK FACTORS AND CURRENT AVAILABLE BEST MEDICAL THERAPY}

Several studies have investigated conventional risk factors for ICAS, mainly in the Asian populations. They are traditionally divided into two major groups: modifiable (arterial hypertension, diabetes mellitus, dyslipidaemia, overweight, physical inactivity, smoking, etc.) and nonmodifiable (age, ethnicity, sex, family history of vascular disease) $[19,41,42]$.

Some studies investigating risk factors for ICAS have shown differences between ICAS and ECAS [43].

Better understanding of risk factors traditionally associated with ICAS may not only explain the presence of ICAS and ethnic differences but may also lead to improved outcome in the case of best medical therapy. The following paragraphs focus on epidemiology and on recommendations for treatment of most prevalent modifiable risk factors in patients with ICAS.

\section{Arterial Hypertension}

Arterial hypertension is one of the most important risk factors for ICAS according to autopsy as well as according to many clinical studies [2, 32, 42, 44, 45]. Studies suggest that Asian and African populations are more prone to high-volume arterial hypertension due to more sodium retention, whereas resistant arterial hypertension is more frequent among Caucasian populations [46]. Arterial hypertension has been reported to cause haemodynamic stress, to accelerate atherosclerosis by injuring vessel endothelium and increasing its permeability for lipoproteins [47]. Intracranial arteries are more prone to damage induced by arterial hypertension than extracranial arteries. This may be explained by the different architecture of the vessel walls. Intracranial arteries consist 
of a thinner media and adventitia, as well as of fewer elastic medial fibres than extracranial arteries [48]. Arterial hypertension has been demonstrated to be associated with occurrence of ICAS as such, with ICAS severity and progression [49].

The WASID trial (Table 1) showed a higher prevalence of recurrent ischaemic stroke among patients with arterial hypertension. Two patients were excluded because of lack of information about blood pressure. All patients had blood pressure measured at baseline and at every 4-month visit. Data revealed the association between arterial hypertension defined as at least $160 / 90 \mathrm{mmHg}$ vs. at least $140 / 90 \mathrm{mmHg}$ and an increased risk of ischaemic stroke not only in the territory of the stenotic vessel $(p=0.0065 / p<0.0001$ vs. $p=0.015 / p<0.0001$ respectively) but also in other vascular territories $(p<0.0001 / p=0.003$ vs. $p=0.0003 /$ $p<0.0001)$. Furthermore, among patients with $50-70 \%$ ICAS, BP of at least $140 / 90 \mathrm{mmHg}$ was associated with a greater risk of any ischaemic stroke $(p<0.0001, p=0.003)$, as well as of ischaemic stroke in the ICAS territory ( $p=0.0002, p=0.010)$, similar to the group at large. Furthermore, during follow-up, 30.7\% of patients with a mean SBP of at least $140 \mathrm{mmHg}$ suffered an ischaemic stroke, myocardial infarction or vascular death, compared to $18.3 \%$ of patients with a mean SBP less than $140 \mathrm{mmHg} \quad(p<0.0005)$ [50]. Multivariable analysis showed that SBP of at least $140 \mathrm{mmHg}$ (HR 1.79, 95\% CI 1.27-2.52; $p=0.0009$ ) was associated with an increased risk (40\%) of a recurrent ischaemic cardio- or cerebrovascular event or vascular death [45]. In the WASID trial (Table 1), elevated mean SBP at enrolment was also found to be associated with presence vs. absence of coexisting asymptomatic ICAS (144.7 $\mathrm{mmHg}$ vs. $139.4 \mathrm{mmHg}, p=0.028$ ) [40].

In the TOSS-II (Trial of cilOstazol in Symptomatic intracranial arterial Stenosis II) study (Table 1), there turned out to be an association between mean SBP levels and progression of ICAS. Patients with normal SBP levels (less than $120 \mathrm{mmHg}$ ) had lowest rates of progression of ICAS $(21.4 \%)$, whereas patients with levels of at least $160 \mathrm{mmHg}$ showed highest rates of progression $(38.9 \%)$ [51, 52].
In the SAMMPRIS (Stenting and Aggressive Medical Management for Preventing Recurrent stroke in Intracranial Stenosis) trial (Table 1), three BP measurements were recorded and averaged at baseline and at each follow-up visit throughout the study [53]. The frequency of BP data collection depended on achievement of the SBP target. The normal schedule of followup visits was every 4 months after the adjustment of antihypertensive regimen according to the target SBP. A post hoc analysis of patients included in the arm of best medical therapy only found that $53 \%$ of these patients had a mean SBP within target (less than $140 \mathrm{mmHg}$ ) during their participation in the study and that they were significantly less likely to have a recurrent ischaemic stroke, myocardial infarction or vascular death (OR 1.3, 95\% CI 1.1-1.7), compared to those who did not reach those targets (OR 2.1, 95\% CI 1.2-4.0) [54].

In the VERiTAS (Vertebrobasilar flow Evaluation and Risk of Transient ischaemic Attack and Stroke) study (Table 1), among 10 subsequent vertebrobasilar territory strokes, seven occurred in patients with BP less than $140 / 90 \mathrm{mmHg}$ compared to three in patients with BP of at least $140 / 90 \mathrm{mmHg}(p=0.33)$. When subgroups were compared according to both BP and haemodynamic status, patients with both low flow and BP less than $140 / 90 \mathrm{mmHg}(n=10)$ had the highest risk of subsequent ischaemic stroke $(n=4, \mathrm{HR} 4.5$, 95\% CI $1.3-16.0 ; p=0.02)$ when compared to all other subgroups combined. After adjustment for the previously identified risk factors for stroke in this cohort, the low flow and BP less than $140 / 90 \mathrm{mmHg}$ subgroup remained at significantly higher risk (HR 7.3, 95\% CI 1.4-37.9; $p=0.02$ ) [55].

Based on the evidence from large randomised trials (WASID, SAMMPRIS), the American Heart Association (AHA)/American Stroke Association(ASA) guidelines of 2014 recommend a BP target of less than $140 \mathrm{mmHg}$ for symptomatic $50 \%$ or higher ICAS of a major intracranial artery (class I; level of evidence B) [56]. Similarly, the European Society of Cardiology (ESC)/European Atherosclerosis Society (EAS) 2019 guidelines also recommend a BP target of less than 140/90 mmHg [57]. However, 
the subgroup of patients with ICAS and low flow might need higher target levels.

\section{Diabetes Mellitus}

Diabetes mellitus has consistently been identified as an independent risk factor for ICAS [2, 42, 44, 58, 59]. Diabetes mellitus has been shown to reduce antioxidant capacity and increase oxidative stress, leading to endothelial dysfunction and inflammation [60].

A couple of decades ago, an autopsy study with consecutive Hong Kong patients $(n=114)$ demonstrated a greater than 50\% ICAS determined by morphometric measurement in autopsy in $31.4 \%$ of patients. The incidence of risk factors (ischaemic heart disease, arterial hypertension, diabetes mellitus, smoking, history of stroke) was obtained by reviewing clinical history and interviewing patients' relatives. Results showed the association of diabetes mellitus as well as of arterial hypertension and age with ICAS [61].

A case-control autopsy study in mostly white consecutive stroke patients $(n=339)$ reported that diabetes mellitus was the only modifiable risk factor associated not only with intracranial atherosclerotic plaques but also with ICAS, defined as a greater than 30\% narrowing of the lumen on the surface section of the arteries [16].

Diabetes mellitus and metabolic syndrome have been reported to be more important risk factors for ICAS than for ECAS and nonatherosclerosis-related stroke (diabetes mellitus: 67\% ICAS, 60\% ECAS, 48\% non-atherosclerotic stroke, and $23 \%$ controls, $p<0.05$ ICAS vs. controls; metabolic syndrome: $62 \%$ ICAS, $40 \%$ ECAS, $40 \%$ non-atherosclerotic stroke, and 35\% controls, $p<0.05$ ICAS vs. controls), according to the Northern Manhattan Stroke Study. In a multivariate analysis, diabetes mellitus conferred a higher risk for ischaemic stroke related to ICAS compared to non-atherosclerotic stroke (OR 10.8, 95\% CI 2.0-57 vs. OR 2.7, 95\% CI $1.9-3.9 ; p<0.05)$ and to ECAS-related stroke (OR 6.2, 95\% CI 1.2-32). The metabolic syndrome also proved to be a risk factor for ischaemic stroke related to ICAS (OR 4.6, 95\%
CI 1.1-18.7) when compared to ECAS (OR 2.3, 95\% CI 0.6-9.1) and non-atherosclerosis (OR 2.4, 95\% CI 1.7-3.3) related stroke [59].

The AsIA study (Table 1) identified diabetes mellitus (OR 2.95, 95\% CI 1.68-5.18; $p<0.001$ ) as the most relevant risk factor for asymptomatic ICAS of any degree and also for moderate to severe asymptomatic ICAS (OR 2.85, 95\% CI 1.16-6.96; $p=0.02$ ) [37]. Another study among asymptomatic Chinese patients suffering from diabetes mellitus with ICAS of one $(n=185)$, both $(n=200)$ or no middle cerebral artery/arteries $(n=1492)$ examined patients with TCD. In $20.6 \%$ of patients with type 2 diabetes mellitus there was evidence of ICAS of the middle cerebral artery on at least one side. Severity of ICAS and increasing number of stenotic vessels were associated with serum glucose or glycated haemoglobin levels (HbA1c), duration of diabetes mellitus, as well as with age, higher SBP and LDL-C levels [62].

In prospective Korean studies, diabetes mellitus was found to be an independent risk factor for ICAS in female patients only after 50 years of age and to show a relation with ICAS in posterior but not in anterior circulation $[32,63]$.

The SAMMPRIS and the WASID trials (Table 1) studied the relationship between better diabetes mellitus control and risk of recurrent ischaemic stroke or vascular events in the follow-up periods of both studies. The protocol of the SAMMPIS trial required testing HbA1c levels in diabetic patients every 6 months in patients with glycaemic control in the target levels and quarterly in patients who were out of the target levels. A post hoc analysis of patients $(n=227)$ included in the best medical therapy arm of the study failed to demonstrate an association between better controlled HbA1c levels (target less than 7.0\%) and recurrence of ischaemic stroke, myocardial infarction and vascular death of other cause (OR 2.0, 95\% CI 0.99-4.1) and with ischaemic stroke (OR 2.3, 95\% CI 1.0-5.0) at 3-year follow-up [54]. These findings are similar to the results of the WASID trial. In this study, the mean HbA1c level in diabetic patients was $8.4 \%$. A total of $91 \%$ of enrolled patients were prescribed insulin or an oral hypoglycaemic agent during follow-up. However, results showed that poor control of 
diabetes mellitus, defined as $\mathrm{HbA1c}$ greater than $7.0 \%$, was not significantly associated with a higher risk of recurrent ischaemic stroke, myocardial infarction or vascular death, nor with recurrent ischaemic stroke alone during follow-up. The risk of ischaemic stroke, myocardial infarction or vascular death was $31 \%$ in diabetic patients with HbA1c greater than $7.0 \% \quad(n=117)$ and $20 \%$ in diabetic patients with good HbA1c control $(n=59)$ [50].

Possible explanations for the failure of the SAMMPRIS and the WASID trial to detect a significant benefit of better HbA1c control may be either a true lack of benefit or a lack of power to detect an effect.

The benefit of better glucose control not only in diabetic patients but also in patients with insulin resistance for lower recurrence of cardio- and cerebrovascular ischaemic events has been demonstrated by the IRIS (Insulin Resistance Intervention after Stroke) trial (Table 1). The possible explanation for the study findings is that pioglitazone improves insulin sensitivity, reduces plasma glucose, reduces biomarkers of systemic inflammation and improves vasomotor reactivity. Also, it has favourable effects on lipid metabolism, blood pressure and thrombosis. The conclusion drawn from this study was that pioglitazone was effective in secondary prevention of recurrent ischaemic stroke in non-diabetic patients with insulin resistance. The study did not analyse ischaemic stroke related to ICAS as such [65].

According to the ESC/EAS 2019 guidelines, HbA1c less than $7 \%$ is recommended for vascular disease prevention [57]. Although the AHA/ASA 2019 guidelines did not set any specific target goals for HbA1c and serum glucose for patients with ICAS, they probably should not differ from those recommended in (atherosclerotic) vascular disease [66].

\section{Dyslipidaemia}

Dyslipidaemia is an important risk factor for ICAS, more even for ECAS [2, 42, 44, 67-69].

In a prospective multicentre study with enrolment of 1000 Korean patients with acute ischaemic stroke or TIA (less than 7 days after onset), which was caused by either ICAS $(n=688)$, ECAS $(n=271)$ or tandem stenoses $(n=41)$, evaluated by CTA, MRA or DSA, dyslipidaemia was identified as the only modifiable risk factor being more prevalent in ECAS (OR $1.50,95 \%$ CI 1.117-2.018, $p=0.007$ ) compared to ICAS [32].

Accumulation of LDL-cholesterol (C) in the intima initiates the development and progression of atherosclerosis and eventually leads to the formation of a plaque. HDL-C plays an antiatherosclerotic role by promoting cholesterol efflux from macrophages, inhibiting oxidation of LDL-C and migration of smooth muscle cells and aggregation of platelets [70]. However, intracranial arteries seem to have a specific glycocalyx composition on endothelial cells that might inhibit the trapping of very low density lipoprotein resulting in reduction of fatty depositions [71]. Ethnicity and environmental factors may influence the effect of dyslipidaemia on atherogenesis of intracranial arteries. Generally, compared to Caucasian populations, Asian and African populations exhibit lower serum lipid levels, which may be one factor explaining the lower incidence of extracranial and coronary atherosclerosis in these populations [72]. Apolipoprotein (apo)-AI, the major apolipoprotein in HDL-C, has antioxidant and anti-inflammatory effects, whereas apo-B represents the total number of potentially atherogenic properties, generates multiple proinflammatory products and aggravates atherogenesis within the vascular wall through oxidation. López-Cancio et al. demonstrated the association between triglyceride/HDL-C ratio and moderate to severe asymptomatic $50 \%$ or higher ICAS, although it was not an independent predictor [37]. A positive correlation between the apo-B/apo-AI ratio and the presence and severity of ICAS has been shown, suggesting that the apo-B/apo-AI ratio may be a promising biomarker for predicting the risk and severity of ICAS [73].

The WASID trial (Table 1) found mean LDLC levels of $3.2 \mathrm{mmol} / \mathrm{l}$ and mean HDL-C levels of $1.1 \mathrm{mmol} / \mathrm{l}$ at baseline. Among all patients enrolled, $61 \%$ were on a statin at baseline and $82.4 \%$ took a statin at any time during the trial. Univariate analysis for the association between 
dyslipidaemia and recurrent ischaemic stroke, myocardial infarction or vascular death demonstrated that total cholesterol levels of at least $5.2 \mathrm{mmol} / \mathrm{l}$ were associated with an increased risk of a major recurrent vascular event $(p=0.0223)$. Furthermore, $25.0 \%$ of patients with LDL-C levels of at least $3.0 \mathrm{mmol} / \mathrm{l}$ suffered an ischaemic stroke, myocardial infarction or vascular death, compared to $18.5 \%$ of patients with mean LDL-C levels less than $3.0 \mathrm{mmol} / \mathrm{l}(p=0.029)$ over the same period. Multivariable analysis showed that total cholesterol level of at least $5.2 \mathrm{mmol} / \mathrm{l}$ (HR 1.44, $1.00-2.07 ; p=0.048$ ) was associated with an increased risk of ischaemic stroke, myocardial infarction or vascular death during the followup period. Also, the results revealed that patients were more likely to suffer a recurrent ischaemic stroke if they had total cholesterol levels of at least $5.2 \mathrm{mmol} / \mathrm{l}$ (HR 2.06, $p=0.0006)$, LDL-C levels of at least $2.6 \mathrm{mmol} / \mathrm{l}$ (HR 1.72, $p=0.0326$ ), non-HDL-C levels of at least $3.4 \mathrm{mmol} / \mathrm{l}(\mathrm{HR} 1.94, p=0.0109)$ and a ratio of total cholesterol/HDL-C levels of at least 4.4 (HR 1.89, $p=0.0043$ ). Furthermore, a total cholesterol of at least $5.2 \mathrm{mmol} / \mathrm{l}$ (HR 1.95, 95\% CI 1.29-2.97; $p=0.002)$ among patients with SBP of at least $140 \mathrm{mmHg}$ (HR 1.58, 1.07-2.32; $p=0.02$ ) was the most important predictor of a recurrent ischaemic stroke. History of dyslipidaemia was independently associated with severe ICAS (OR 1.62, 95\% CI 1.09-2.42; $p=0.02$ ). Furthermore, patients with ICAS of the basilar artery were most likely to have dyslipidaemia (70.86\% vs. $64.81 \%$ with intracranial ICAS of the internal carotid artery, $57.71 \%$ with ICAS of the middle cerebral and $63.81 \%$ with ICAS of the vertebral artery; $p=0.054)[45,74]$.

The SAMMPRIS trial (Table 1) had LDL-C levels below $1.8 \mathrm{mmol} / \mathrm{l}$ as a primary risk factor target, as well as non-HDL-C levels below $2.6 \mathrm{mmol} / \mathrm{l}$ as a secondary target, with standardised measurements at baseline, 30 days and at 4 months, by using a central core lipid laboratory. Among all patients enrolled in the best medical therapy arm of the trial, a total of $47 \%$ had a mean target of LDL-C levels below $1.8 \mathrm{mmol} / \mathrm{l}$ and $60 \%$ of non-HDL-C levels below $2.6 \mathrm{mmol} / \mathrm{l}$. According to the post hoc analysis of the conservatively treated patients, lower continuous LDL-C and lower non-HDL-C levels were associated with lower likelihood of recurrent ischaemic stroke, myocardial infarction or vascular death, as well as of recurrent ischaemic stroke alone until 3-year follow-up [54].

According to the SPARCL (Stroke Prevention by Aggressive Reduction in Cholesterol Levels) trial (Table 1), which was not specific to patients with ICAS, reduction of LDL-C levels below $1.81 \mathrm{mmol} / \mathrm{l}$ was associated with a $28 \%$ reduction in risk of ischaemic stroke compared with a level above $2.59 \mathrm{mmol} / \mathrm{l}$ [75]. A post hoc analysis investigating atorvastatin vs. placebo showed atorvastatin $80 \mathrm{mg} /$ day to be effective in reducing recurrence risk of ischaemic stroke among patients with atherosclerotic large vessel disease. However, the SPARCL trial was underpowered for subgroup analyses.

A randomised parallel-group event-driven study assigned a total of 2860 patients with a recent (less than 3 months) ischaemic stroke or a TIA (less than 15 days) to a target LDL-C level of below $1.8 \mathrm{mmol} / \mathrm{l}$ (lower-target group, $n=1430$ ) or to a target range of $2.3-2.8 \mathrm{mmol} / \mathrm{l}$ (higher-target group, $n=1430$ ) [76]. All patients enrolled had either ECAS, ICAS, atherosclerotic plaques of the aortic arch (4 mm or larger) or a known history of coronary artery disease. The primary endpoint was defined as ischaemic stroke, myocardial infarction, new symptoms leading to urgent coronary or carotid revascularisation or death from vascular causes during the follow-up period of 3.5 years. Achieved LDL$\mathrm{C}$ targets of $1.8 \mathrm{mmol} / \mathrm{l}$ were related to a lower risk of major vascular events, compared to higher LDL-C levels $(n=121,8.5 \%$ in the lowertarget group vs. $n=156,10.9 \%$ in the highertarget group [HR 0.78 (0.61-0.98), 95\% CI, $p=0.04])$.

AHA/ASA 2019 guidelines recommend highintensity statin therapy, independent of baseline LDL-C levels, to reduce the risk of vascular events for patients up to 75 years of age with cerebrovascular ischaemic events of atherosclerotic origin and without contraindications. Also, they recommend moderate intensity statin therapy for those over 75 years of age or for those with conditions influencing statin safety or a history of statin intolerance [66]. 
According to the ESC/EAS 2019 guidelines a therapeutic regimen that achieves at least a 50\% LDL-C reduction and a LDL-C goal of below $1.4 \mathrm{mmol} / \mathrm{l}$, non-HDL-C less than $2.2 \mathrm{mmol} / \mathrm{l}$, triglycerides less than $1.7 \mathrm{mmol} / \mathrm{l}$ and apo-B less than $0.0013 \mathrm{mmol} / \mathrm{l}$ for very high risk patients is recommended for the management of dyslipidaemia. Very high risk patients are defined as those with documented atherosclerotic cardiac disease, as well as those after a cerebrovascular event [57].

Although there are no secondary prevention recommendations about target lipid levels in patients with ICAS, for patients with an ischaemic stroke or TIA attributable to $50 \%$ or higher stenosis of a major intracranial artery, high intensity statin therapy is recommended (class I; level of evidence B), according to AHA/ ASA 2014 guidelines [56].

\section{Overweight and Physical Inactivity}

Obesity, defined as a body mass index (BMI) of $30 \mathrm{~kg} / \mathrm{m}^{2}$ or higher is an established risk factor for stroke [77].

BMI was recorded at every visit in the SAMMPRIS trial (Table 1). Only 19\% of patients enrolled in the best medical therapy arm of the study were in the BMI target (from baseline until adverse event or close-out), defined as BMI less than $25 \mathrm{~kg} / \mathrm{m}^{2}$ for patients with initial BMI between $25-27 \mathrm{~kg} / \mathrm{m}^{2}$ and reduction of body weight by $10 \%$ for patients with initial BMI greater than $27 \mathrm{~kg} / \mathrm{m}^{2}$. Results from the post hoc analysis demonstrated that control of BMI did not have a significant effect on the 3-year rates of ischaemic stroke, myocardial infarction or vascular death (OR 0.9, 95\% CI 0.4-2.0), nor on the 3-year rate of ischaemic stroke alone (OR $0.9,95 \%$ CI 0.4-2.1) [54].

Physical activity has been proven to be of benefit, reducing risk factors and risk of stroke [78].

Physical activity was assessed in the SAMMPRIS trial (Table 1) according to the 8-point Physician-based Assessment and Counseling for Exercise (PACE) questionnaire, which the participants completed at each visit [79]. Moderate exercise included activities like brisk walking or slow cycling for at least $10 \mathrm{~min}$ at a time, whereas vigorous exercise consisted of jogging or fast cycling for at least $20 \mathrm{~min}$ at a time. Walking turned out to be the most common form of exercise at all time points, as measured by both the duration of exercise and the number of patients performing the exercise. The mean duration of walking and other aerobic activities increased significantly from baseline to all other time points. Physical activity out of target was defined as a PACE score of 3 or less ( 3 = trying to do vigorous or moderate exercise but not exercising regularly, $2=$ no vigorous or moderate exercise but thinking of starting in next 6 months, and $1=$ no vigorous or moderate exercise and no intention to start in next 6 months). Results from the post hoc analysis of the patients enrolled in the best medical therapy arm only revealed that for the endpoint of ischaemic stroke alone over the follow-up of 3 years, physical activity was the only risk factor associated with fewer events (OR 0.5, 95\% CI 0.4-0.7). Furthermore, participants who were reaching the target for physical activity were significantly less likely to have a recurrent vascular event over the follow-up period compared to those who did not achieve those targets. The conclusion was drawn that while arterial hypertension and dyslipidaemia may contribute to the risk of recurrent vascular ischaemic events, the independent effect of physical activity was stronger for the prediction of vascular events. Notably, physically inactive patients had up to five times the likelihood of having an ischaemic stroke, myocardial infarction or vascular death, as well as a sixfold increased risk of an ischaemic stroke compared to physically active patients.

According to AHA/ASA 2014 guidelines all patients with a cerebrovascular ischaemic event should be screened for obesity with measurement of BMI (class I; level of evidence C) [56]. Despite the shown beneficial effects of weight loss on risk factors, the usefulness of weight loss among patients with a recent cerebrovascular ischaemic event and obesity is uncertain (class IIb; level of evidence C). Since the association between obesity and increased risk for ischaemic stroke may be largely explained by the intermediate risk factors, the consequences 
of obesity are controversial and not well established yet.

AHA and ACC recommend that adults participate in 3-4 sessions of aerobic physical activity a week, lasting an average of $40 \mathrm{~min}$ and involving moderate (e.g. brisk walking) or vigorous (e.g. jogging) intensity [80].

According to ESC/EAS 2019 guidelines a total of 3.5-7 h moderately vigorous physical activity per week or 30-60 min most days is the target goal for vascular disease prevention [57].

Although there are no secondary prevention recommendations about physical activity which are specific to patients with ICAS, these patients may also benefit from regular exercise, as mentioned above. However, it should be taken into consideration that low flow patients should rather avoid intensive physical activity.

\section{Smoking}

Smoking is widely accepted as a major risk factor, increasing the risk of ischaemic stroke twoto fourfold. Pathophysiologically it increases blood pressure, heart rate and oxidative stress [81].

It has been reported to play an important role both in patients with ICAS [2] and in those with ECAS [82]. However, a randomised prospective study in patients $(n=989)$ with an acute ischaemic stroke or TIA and ICAS detected by MRA concluded that smoking may be more strongly associated (OR 1.83, 95\% CI 1.07-3.16, $p=0.026)$ with ICAS $(32.9 \%)$ than with ECAS (28.2\%) [83]. Smoking has been shown to correlate with ICAS progression and severity [84, 85].

Although in the SAMMPRIS and WASID trials (Table 1) smoking was recorded at all study visits, post hoc analyses of both studies failed to demonstrate the benefit of its control for reducing the rate of recurrent vascular events.

According to AHA/ASA 2014 guidelines, smokers with a cerebrovascular event should receive in-hospital initiation of high-intensity behavioural interventions to promote smoking cessation and for smokers with an acute ischaemic stroke, nicotine replacement therapy is recommended (class IA; level of evidence A).
Furthermore, healthcare providers should strongly advise every patient who smokes to quit (class I; level of evidence C-EO) [66].

Although there are no secondary prevention recommendations about smoking which are specific to patients with ICAS, smoking cessation should be aimed for.

\section{Healthy Lifestyle}

Lifestyle modification is crucial for achievement of risk factors targets in patients with ICAS.

SAMMPRIS was the first trial (Table 1) which provided a commercially available telephonic lifestyle modification program (INTERxVENT) free of charge for all patients during study participation. Lifestyle coaches provided individualised risk factor advice twice a month for 6 months and monthly thereafter during the follow-up period. Patients were divided into compliant patients $(n=201)$, who had at least $78.5 \%$ of calls and into noncompliant patients with less than $78.5 \%$ of calls $(n=200)$. There was a significant difference between compliant vs. noncompliant patients in the change in HbA1c from baseline to 6 months $(-0.7 \% \pm 1.9 \%, \quad n=59 \quad$ vs. $\quad 0.2 \% \pm 2.7 \%$, $n=58 ; p=0.04)$ and in the change in SBP from baseline to 24 months $(-18.4 \pm 21.6 \mathrm{mmHg}$, $n=171$ vs. $\quad-11.2 \pm 23.5 \mathrm{mmHg}, \quad n=130$; $p=0.006)$. They also differed in the change from baseline to 36 months $(0.3 \pm 0.4 \mathrm{mmol} / \mathrm{l}$, $n=55$ vs. $0.1 \pm 0.3 \mathrm{mmol} / \mathrm{l}, n=17 ; p=0.03$ ) for HDL-C levels. However, there was no difference for BMI [86]. These results demonstrate that healthy lifestyle leads to better control of several risk factors.

Healthy living, including healthy diet and regular physical activity, has also been recommended by AHA/ASA 2019 guidelines for all patients after an acute ischaemic stroke [66]. Patients with ICAS should also aim at a healthier lifestyle as part of secondary prevention.

\section{Age, Ethnicity and Genetics}

Results of the AsIA study (Table 1) identified age (OR 1.05, 95\% CI 1.004-1.1; $p=0.03$ ) to be 
associated with moderate to severe asymptomatic ICAS [37].

There is controversial data on studies on the prevalence of ICAS in patients at different age. Autopsy and imaging studies have found that ICAS is more prevalent later in life than ECAS $[16,32]$. One of the potential explanations is related to the greater antioxidant enzyme activity at younger age in intracranial arteries, making them more resistant to atherosclerotic plaques [87].

Potential reasons for ethnic differences in the prevalence, severity and location, but also in the pathogenesis and prognosis of ICAS may partially be explained by differences in risk factor profiles [88]. For instance, higher rates of obesity and hyperglycaemia as well as lower rates of physical activity are more typical for Hispanic rather than for Caucasian populations [89]. Also, studies demonstrated Asian populations to have a higher prevalence of arterial hypertension, smoking and visceral obesity, associated with insulin resistance $[90,91]$.

Also, polymorphisms such as for adipocytokines, lipoprotein lipase and C-reactive protein have been described to be present in patients with ICAS but also ECAS [92].

Moreover, the ring finger protein 213 (RNF213) has been shown to be a susceptibility gene not only for moyamoya disease but also for ICAS. In a meta-analysis (11 studies, 1778 patients with ICAS), the variant RNF213 p.R4810K has been found to increase the risk of ICAS in Chinese patients (OR 5.59, 95\% CI $2.12-14.75 ; p=0.001$ ), with significantly lower effect size than in Japanese and Korean patients (OR 10.71 and 28.52, 95\% CI 3.97-28.91 and 11.04-73.67, respectively). The variant RNF213 p.R4810K is absent in non-Asian populations. Other variants of RNF213 have been identified to be associated with ICAS [93].

\section{Anticoagulation and Antithrombotics}

Blood thinning is of crucial importance in therapy of patients with ICAS. Anticoagulation interferes with the coagulation cascade, and antithrombotics interfere with platelet activation and aggregation.
Anticoagulants have empirically been used for patients with severe occlusive disease in the vertebrobasilar arteries and in recurrent ischaemic stroke according to favourable results of clinical trials several decades ago [94].

However, the WASID trial (Table 1) showed a benefit of antiplatelet treatment over anticoagulation in patients with non-disabling ischaemic stroke or TIA within 90 days before randomisation, attributable to 50-99\% ICAS. This occurred even though the dosage of aspirin was considerable (1300 mg/day). This high dosage of aspirin was prescribed because of its supposed better ability to decrease platelet resistance $[95,96]$, to diminish shear-induced platelet aggregation [97] and to decrease the inflammatory component of atherothrombosis [98-101].

Since non-vitamin $\mathrm{K}$ antagonist oral anticoagulants (NOACs) have been shown to be safer than vitamin $\mathrm{K}$ antagonists (warfarin) in secondary stroke prevention [102-105], the question arises whether NOACs would be effective and safe in patients with ICAS. There is a need for clinical trials addressing NOACs in this specific patient group.

The CLAIR (Clopidogrel plus Aspirin for Infarction Reduction) study (Table 1) investigated dual antiplatelet therapy for reduction of microembolic signals (MES) detected by TCD [106]. MES have been described to be a surrogate marker for higher risk of cerebrovascular ischaemic events. All patients had at least 50\% symptomatic ECAS or ICAS of the internal carotid artery or ICAS of the middle cerebral artery. Results from this study indicate that dual antiplatelet therapy for 7 days is more effective with a comparable safety than aspirin alone for reducing the number of MES in acute stroke or TIA patients with ICAS, which might be related to a decreased risk of cerebrovascular ischaemic events.

A substudy of the CHANCE (Clopidogrel in High-risk patients with Acute Nondisabling Cerebrovascular Events) trial (Table 1) analysed the efficacy of dual antiplatelet therapy among symptomatic patients with ICAS, compared to patients without ICAS. Results indicated higher rates of recurrent ischaemic or haemorrhagic stroke in minor ischaemic stroke or high-risk 
TIA patients with ICAS than in those without. However, there was no significant difference in the response to and concerning safety of the two antiplatelet regimes between patients with and without ICAS [107, 108].

The GESICA (Groupe d'Etude des Sténoses Intra-Crâniennes Athéromateuses symptomatiques) trial (Table 1) evaluated the benefit of medical therapy in patients with minor ischaemic stroke or TIA within 6 months and related to at least 50\% ICAS [7]. Patients were treated with a single antiplatelet agent, with one antiplatelet and one anticoagulant, with one anticoagulant or with other antithrombotic combinations of antithrombotics and anticoagulants. There was a considerable recurrence rate of ischaemic stroke in the territory of the ICAS but also of other vascular events. Also, the study found an association between ICAS and coronary artery and peripheral arterial disease. Among 20 patients who underwent angioplasty there was one fatal haemorrhagic stroke, which occurred 2 months after the procedure.

In the SAMMPRIS trial (Table 1), including patients with non-disabling ischaemic stroke or TIA caused by 70-99\% ICAS, lower rates of any stroke or death was found in the best medical therapy group compared to the percutaneous transluminal angioplasty and stenting (PTAS) group.

The VISSIT (Vitesse Intracranial Stent Study for Ischaemic stroke Therapy) study (Table 1) also supported the benefit of best medical therapy within 30 days in patients with symptomatic $70 \%$ or higher ICAS [109].

Cilostazol is an alternative antiplatelet having been investigated in patients with ICAS. It is a phosphodiesterase 3 inhibitor with vasodilating, anti-inflammatory, anti-atherogenic effects and a low bleeding risk. The TOSS I (Trial of cilOstazol in Symptomatic intracranial arterial Stenosis) study (Table 1) randomised Korean patients with symptomatic ICAS either to cilostazol (100 mg twice daily) or placebo. All participants received aspirin $100 \mathrm{mg} /$ day additionally [110]. Results demonstrated that cilostazol may not only prevent ICAS progression, but may even potentiate regression of ICAS. Furthermore, no ischaemic or haemorrhagic stroke or TIA occurred in both groups during the study period of 6 months.

However, the TOSS II study (Table 1) failed to find a benefit of cilostazol (100 mg twice daily) and of aspirin (75-150 mg once daily) over clopidogrel (75 mg once daily) and aspirin (75-150 mg once daily) in preventing progression of ICAS and occurrence of new ischaemic lesions in the territory of ICAS in the follow-up MRI at 7 months [52]. Safety assessment revealed that major haemorrhagic complications were not significantly different between both groups.

Although both TOSS I and II studies have limitations including evaluation of radiological markers only but not of clinical events, Korean ethnicity of all included patients, short followup periods and small number of enrolled patients, cilostazol is currently widely prescribed in patients with ICAS, mostly in Asia.

Ticagrelor is another antiplatelet acting as a platelet $\mathrm{P}_{2} \mathrm{Y}_{12}$ receptor antagonist which has been studied among patients with non-cardioembolic minor ischaemic stroke or TIA in the SOCRATES (Acute Stroke Or Transient isChaemic attack tReated with Aspirin or Ticagrelor and patient outcomES) study [111]. Patients were randomised to receive either ticagrelor (180 mg loading dosage on day 1 followed by $90 \mathrm{mg}$ twice daily for 90 days) or aspirin (300 mg on day 1 followed by $100 \mathrm{mg}$ /day for 90 days). Although the trial failed to show superiority of ticagrelor over aspirin, it has been suggested e.g. to be prescribed in carriers of loss-of-function alleles, causing potential resistance to clopidogrel or in patients with recurrent cerebrovascular ischaemic events.

A substudy of SOCRATES $(n=3081)$ (Table 1$)$ has focused on ischaemic strokes caused by ipsilateral atherosclerotic disease. In this substudy, ticagrelor was superior to aspirin in preventing recurrent ischaemic or haemorrhagic stroke, myocardial infarction or death at 90 days in patients with acute ischaemic stroke or transient ischaemic attack when associated with ipsilateral ICAS. There were no significant differences in the proportion of life-threatening, major or minor haemorrhages between both groups [112]. 
Prasugrel, which is another antiplatelet and platelet $\mathrm{P}_{2} \mathrm{Y}_{12}$ receptor antagonist, has been compared to clopidogrel among Japanese patients with non-cardioembolic ischaemic stroke (within up to 1-26 weeks before inclusion) in the PRASTRO-I (PRAsugrel and clopidogrel in Japanese patients with ischemic STROke) study (Table 1) [113]. Patients were randomly assigned to either prasugrel ( $3.75 \mathrm{mg}$ /day) or clopidogrel (75 mg/day) orally. This study did not confirm non-inferiority of prasugrel compared to clopidogrel for the prevention of ischaemic stroke, myocardial infarction and death from other vascular causes in Japanese patients with non-cardioembolic stroke. No safety concerns were identified. Although a total of $29 \%$ of enrolled patients had large artery atherosclerosis, the specific location was not described in this study.

According to AHA/ASA 2019 guidelines, for patients with non-cardioembolic acute ischaemic stroke the use of antithrombotics rather than oral anticoagulation is recommended to reduce risk of vascular events (class I; level of evidence A) [66].

According to AHA/ASA 2014 guidelines, for patients with an ischaemic stroke or TIA associated with at least 50\% ICAS of a major intracranial artery, aspirin $325 \mathrm{mg} /$ day is recommended in secondary prevention in preference to warfarin (class I; level of evidence B). In at least 70\% ICAS, the AHA/ASA 2014 guidelines state that the addition of clopidogrel $75 \mathrm{mg}$ /day to aspirin $100 \mathrm{mg} /$ day for 90 days might be reasonable (class IIb; level of evidence B) [56].

According to AHA/ASA 2014 guidelines for patients with ischaemic stroke or TIA attributable to a $50 \%$ or higher ICAS of a major intracranial artery, the data are insufficient to make a recommendation in secondary stroke prevention regarding the usefulness of clopidogrel alone, the combination of aspirin and dipyridamole or cilostazol alone (class IIb; level of evidence C) [56].

\section{ENDOVASCULAR THERAPY}

The question arises whether endovascular therapy is safe and effective in patients with ICAS since considerable recurrence rates of cerebrovascular ischaemic events have been reported despite best medical therapy [114].

The small calibres of cerebral arteries, the relative paucity of supporting medial and adventitia layers, the presence of end-anastomosing perforator branches and the vascular tortuosity demand specialized interventional skills and devices [11]. As a result of the diverse stroke mechanisms of ICAS, careful patient selection, according to the underlying pathophysiological pattern, and evaluation of the indications and procedural risks and benefits are crucial prior to deciding on endovascular procedure. The treatment indications will likely develop in parallel with future advancement of endovascular techniques and better understanding of ICAS.

Various endovascular therapy strategies have been applied in patients with ICAS in recent years. The first and most simple endovascular therapy initiated was the balloon angioplasty alone. It dilated the calibre of the ICAS, leading to increase of perfusion in the downstream territory. In 1980, two patients with frequent, severe, progressive symptoms despite anticoagulation and high-grade ICAS of the basilar artery got treated by cerebral transluminal balloon catheter dilatation [115]. The excellent angiographic and short-term clinical results in these two patients as well as the prevalence of ICAS favoured further research of this approach. Unfortunately, arterial dissection with consecutive thrombosis or rupture, residual stenosis due to sequestration or vessel recoiling and acute or subacute vascular occlusion due to the formation of a wall haematoma were reported as frequent complications in the next case series [116].

In order to reduce periprocedural complications of angioplasty alone, the rigid coronary Palmaz-Schatz stent was applied for the first time in 1996 in a patient with recurrent TIA due to severe ICAS of the right carotid artery despite antiplatelet and anticoagulant therapy [117]. Deploying the stent led to a better angiographic result compared to angioplasty alone. The patient was asymptomatic 4 months after the procedure. However, probably as a result of the rigidness of the coronary stent a high rate of up 

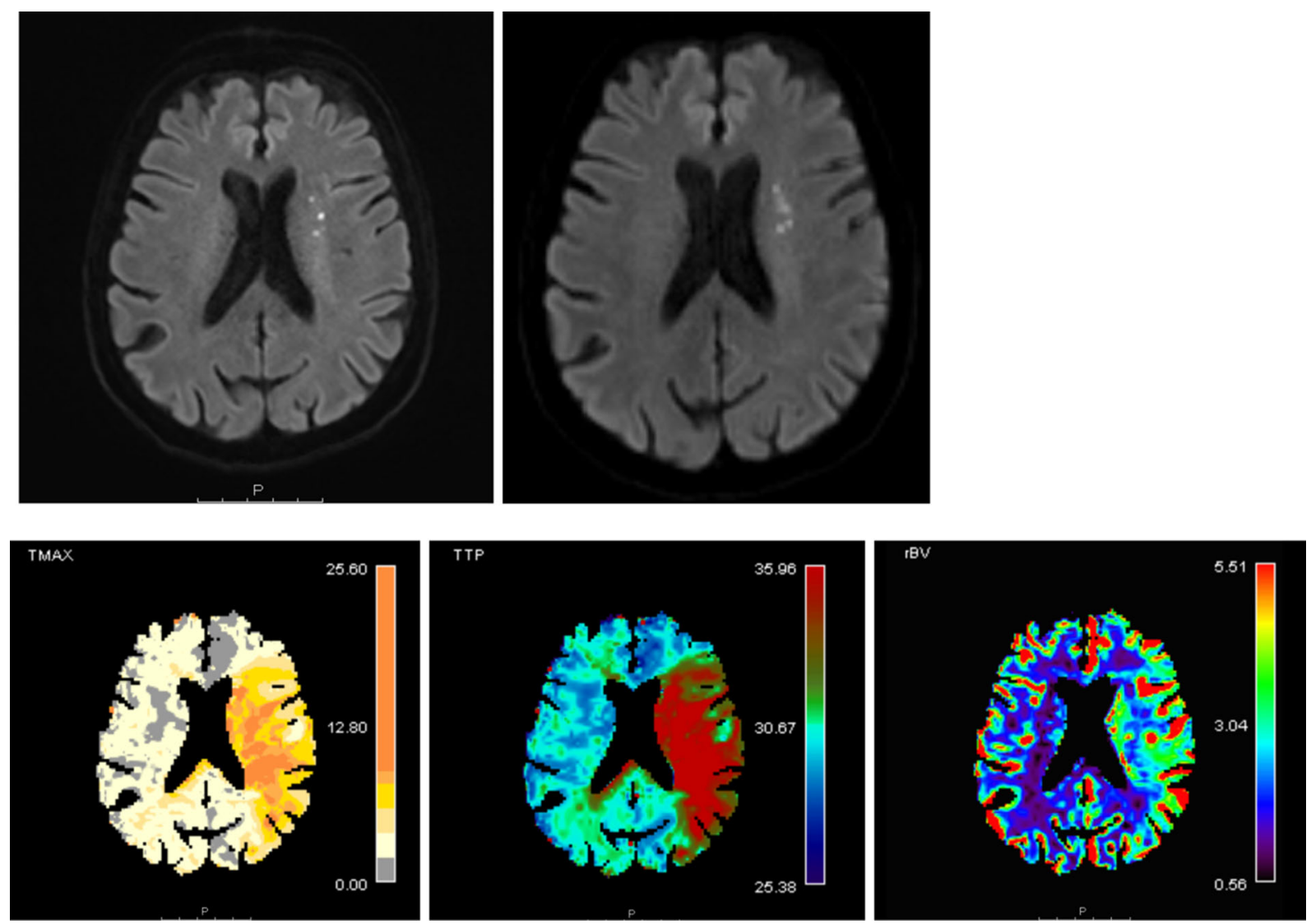

Fig. 2 MRI of a patient with high-grade ICAS of the middle cerebral artery on the left side causing hypoperfusion downstream and recurrent ischaemic stroke despite best medical therapy

to $30 \%$ procedure-related complications has been described in various case series [118].

In a retrospective single-centre trial in patients $(n=120)$ with ischaemic stroke or TIA attributable to $50 \%$ or higher ICAS measured by DSA, primary angioplasty was associated with a combined periprocedural ischaemic stroke and death rate of $5.8 \%$. In the mean follow-up period of 42.3 months there were $6(3.2 \%)$ patients with an ischaemic stroke in the territory of treatment and $5(4.4 \%)$ patients with ischaemic stroke outside the territory of the treated stenotic vessel [119].

In 2004, the SSYLVIA (Stenting of SYmptomatic Atherosclerotic Lesions in the Vertebral or Intracranial Arteries) trial (Table 1) was the first multicentre, non-randomised, prospective study using the balloon-expandable Neurolink stent system (Guidant, Indianapolis, IN, USA) in patients with symptomatic $50 \%$ or higher ICAS
(70.5\%) or ECAS (29.5\%) [120]. The study showed that the Neurolink stent system was associated with a high rate of successful stent deployment.

Thereafter, in 2005 the first self-expanding, nitinol-composed Wingspan stent (Boston Scientific, Fremont, CA, USA) was approved by the US Food and Drug Administration (FDA) for patients with $50 \%$ or higher ICAS, symptomatic despite medical therapy.

The first randomised trial assessing best medical therapy with/without the Wingspan stent system in patients with non-disabling ischaemic stroke or TIA caused by 70-99\% ICAS is the SAMMPRIS trial (Table 1) [53, 121]. Best medical therapy was superior to PTAS with the use of the Wingspan stent system, both because the risk of any early stroke after PTAS was high and because the risk of any stroke with best 

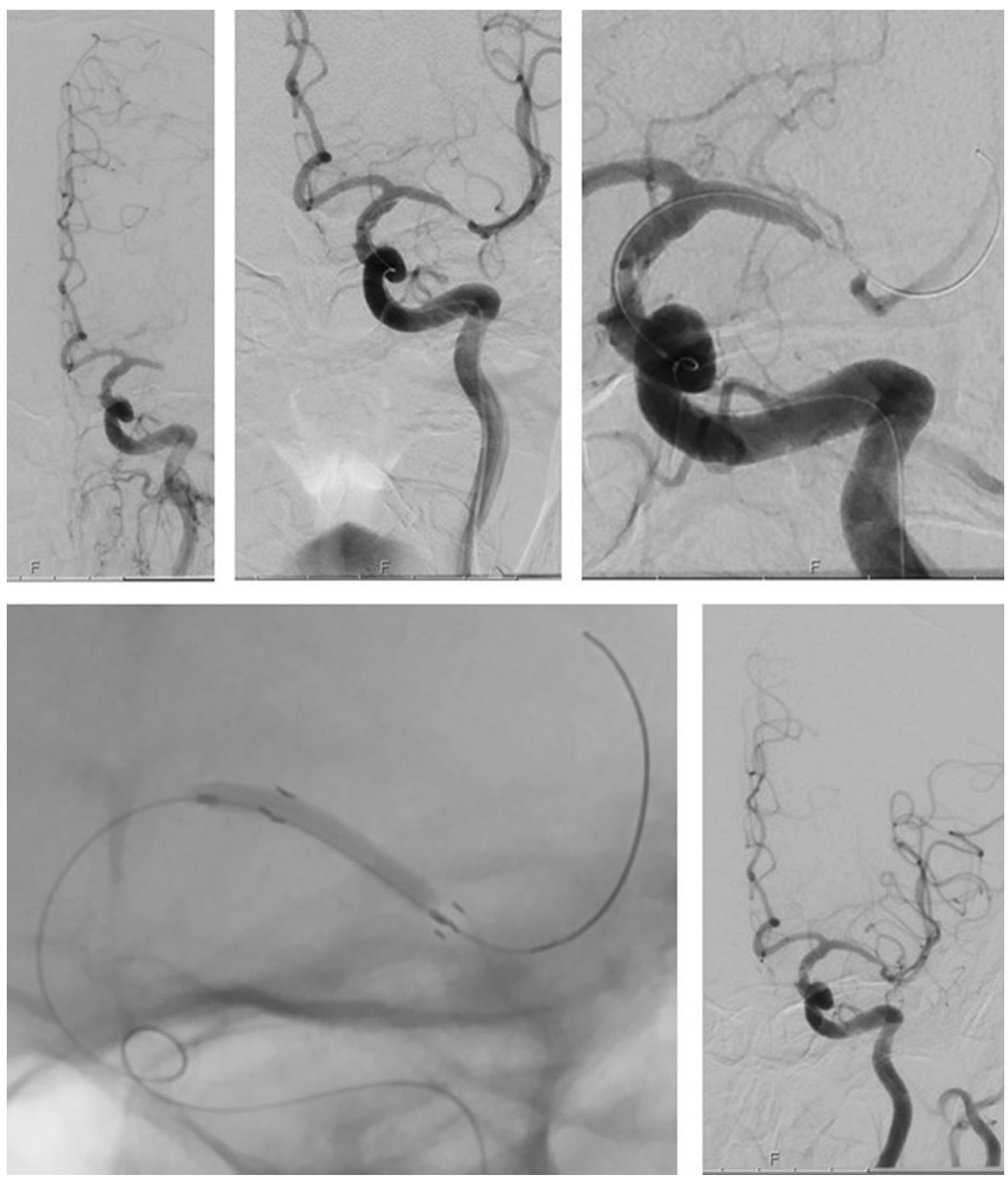

Fig. 3 DSA of a patient with ICAS-related acute large vessel occlusion of the middle cerebral artery on the left side and prompt reocclusion after initial reperfusion, then

medical therapy alone was lower than expected [122].

Major criticisms about the SAMMPRIS trial were as follows: experience of interventionalists was not optimal. Also, 35.3\% of patients included in the PTAS group of the SAMMPRIS trial had not previously failed antithrombotic therapy, which was contrary to the FDA criteria (deployment of the self-expanding Wingspan undergoing intra-arterial infusion of glycoprotein IIb/IIIa inhibitor and permanent deployment of a stent retriever with angioplasty

stent only in patients having suffered at least two ischaemic strokes, attributable to $50 \%$ or higher ICAS, while receiving antithrombotic therapy) [122]. Patients with only one ischaemic lesion attributable to $70 \%$ or lower ICAS and without MES detected on TCCD may benefit from the maximal-dosage dual antiplatelet therapy, intensive risk factor control and rigorous lifestyle management, including control of 
BMI, smoking cessation and regular physical activity. However, patients with generalized atherosclerotic disease, $70 \%$ or higher ICAS, who had recurrent cerebrovascular ischaemic events due to underlying hypoperfusion with/ without poor collaterals may benefit more from endovascular therapy. However, the SAMMPRIS trial did not show a benefit in the subgroup of patients with cerebrovascular ischaemic events with underlying hypoperfusion with/without poor collaterals $[123,124]$. But, the small sample size of this subgroup analysis limits this finding.

Most patients in the PTAS group were treated in the acute or subacute stage with median time from the qualifying event to randomisation of 7 days (interquartile range 4-16 days). In this time period, atherosclerotic plaques of ICAS might show a certain instability. These patients might benefit from endovascular therapy since their plaques might not stabilize with best medical therapy alone and cause recurrent artery-to-artery embolic strokes. Also, unstable plaques might be dislodged into the orifice of perforators in endovascular therapy $[125,126]$. Besides, stents might occlude orifices of perforators by themselves.

Furthermore, among 224 patients in the PTAS group of the SAMMPRIS trial, $61.2 \%$ had lesions in the anterior circulation and the remaining $(38.8 \%)$ in the posterior circulation. Data from a systematic review including 31 studies and 1177 symptomatic patients with at least 70\% ICAS receiving stenting demonstrated a significantly lower rate of occurrence of any stroke or death in the anterior circulation compared to the rate in posterior circulation ICAS (6.6 vs. $12.1 \%$, 95\% CI $1.21-3.10$; $p=0.006)$. The small diameter and angulation of the vertebrobasilar arteries, which is associated with a higher degree of technical complexity, might have contributed to the increased periprocedural complication rates observed in posterior circulation. Furthermore, the probability that a stent covers the ostia of perforators and thereby leads to a subsequent ischaemic stroke is higher in posterior circulation than in anterior circulation [127].

So, it might be of importance to take the initial composition of ICAS and the precise underlying cerebrovascular ischaemic event mechanism into consideration. Also, high professional expertise of interventionalists and application of different endovascular procedures and different stents deployed might facilitate beneficial outcomes [11].

Similar results as in SAMMPRIS have been demonstrated by the VISSIT (Vitesse Intracranial Stent Study for Ischaemic Stroke Therapy) study (Table 1), which included patients with symptomatic 70-99\% ICAS and compared balloon-expandable stenting with the Pharos stent system plus best medical therapy and best medical therapy alone [109]. In this study, the use of a balloon-expandable stent compared with best medical therapy resulted in an increased 12-month risk of ischaemic stroke or TIA in the same territory, and increased 30-day risk of any stroke or TIA. These findings did not support the use of a balloon-expandable stent for patients with symptomatic ICAS.

Criticisms about the VISSIT trial were quite similar as in the SAMMPRIS trial. In particular the heterogeneity of included patients and the non-optimal experience of interventionalists are comparable.

Regarding atherosclerotic stenosis of vertebral arteries, the VIST (Vertebral artery Ischaemia Stenting Trial) trial compared vertebral angioplasty and stenting (balloon-expandable or self-expandable stent) with best medical therapy in patients with symptomatic $50 \%$ or higher ECAS (mostly affecting the V1 segment) in $83 \%$ of patients and at least $50 \%$ ICAS in $17 \%$ of patients [128]. The study demonstrated safety of stenting for ECAS.

Low periprocedural risk in stenting of $50 \%$ or higher vertebral ECAS/ICAS has been revealed in VAST (Vertebral Artery Stenting Trial) (Table 1). Patients were randomised to stenting (with choice of stent at the discretion of the interventionalist) or PTA alone if stent placement turned out not to be feasible or contraindicated after the beginning of the intervention) plus best medical therapy and best medical therapy alone. There were $16 \%$ of patients with ICAS in the stenting group and $17 \%$ in the best medical therapy group. Endovascular therapy in this study was associated with a major periprocedural vascular 
complication in about one in 20 patients. In the patients studied, the risk of any recurrent stroke under best medical treatment alone was low. It should be pointed out that more than $80 \%$ of patients included in the study had ECAS [129].

The WEAVE (Wingspan stEnt system postmArket surVEillance) trial (Table 1), which enrolled patients with 70-99\% ICAS, baseline mRS score 3 or less, at least two ischaemic strokes (at least one of which while on best medical therapy) in the vascular territory of the ICAS and stenting of the ICAS at least 8 days after last ischaemic stroke, is the largest up to date on-label trial for the self-expandable Wingspan stent system in patients with ICAS [130]. Results demonstrated safety of the Wingspan stent system. The rate of any stroke or death was lower than the target of $4 \%$ periprocedural safety set by the FDA. Since the design of the Wingspan stent has not substantially changed since its introduction into the market in 2005, the results of the WEAVE study have been explained by good experience of interventionalists as well as by favourable selection of patients meeting the criteria for stenting by strictly following the on-label indications.

CASSISS (China Angioplasty and Stenting for Symptomatic Intracranial Severe Stenosis) is an ongoing study (Table 1), which aimed to enrol 380 patients with recent ischaemic stroke or TIA caused by $70-99 \%$ ICAS of a major intracranial vessel [131]. The recruitment was complete in November 2017. The study compares best medical therapy with/without stenting using the Wingspan stent system. It is noteworthy that patients recruited in the CASSISS trial suffered their last ischaemic stroke after more than 3 weeks in order to lower periprocedural risk of stenting. Also, patients with perforator stroke without distal hypoperfusion with/without poor collaterals or artery-to-artery embolism according to MRI were excluded from the study.

Length of ICAS, procedural arterial access and diameter of culprit arteries and proximity of the plaque and lenticulostriate perforators should also be considered before deciding on the most accurate type of endovascular therapy. According to the Mori classification, three different types of stenoses are subclassified:
Mori A-a short and concentric lesion with a short length (less than $5 \mathrm{~mm}$ ); Mori B-a tubular or extreme eccentric lesion, at most 3 months old, with intermediate length (between 5 and $10 \mathrm{~mm}$ ) and Mori C-a diffuse lesion, at least 3 months old, with a long length greater than $10 \mathrm{~mm}$ and angled more than $90^{\circ}$ [132]. Regarding these lesion characteristics balloon-mounted stents may be more suitable for patients with smooth arterial access and Mori A ICAS, midbasilar artery ICAS and ICAS of the distal M1 segment of the middle cerebral artery; self-expanding stents for patients with tortuous arterial access and Mori B or C ICAS and balloon angioplasty alone for patients with tortuous arterial access with Mori A ICAS and a small target-vessel diameter of less than $2.5 \mathrm{~mm}$ [133].

According to AHA/ASA 2014 guidelines, for patients with an ischaemic stroke or TIA attributable to $70-99 \%$ ICAS of a major intracranial artery, stenting with the Wingspan stent system is not recommended as an initial treatment, even for patients who were taking an antithrombotic agent at the time of ischaemic stroke or TIA (class III; level of evidence B). Furthermore, even for patients with 70-99\% ICAS of a major intracranial artery and actively progressing symptoms after institution of aspirin and clopidogrel therapy, the usefulness of angioplasty alone or placement of a Wingspan stent or other stents is unknown and still considered investigational (class IIb; level of evidence C) [56].

At present, we suggest that endovascular therapy may be considered as a treatment option for patients with recurrent ischaemic stroke (Fig. 2) despite best medical therapy and especially if pathophysiologically attributed to hypoperfusion with/without bad collaterals. The most appropriate type of endovascular therapy should be performed for every patient individually according to the underlying pathophysiological cerebrovascular ischaemic event mechanism and according to characteristics of ICAS. In future, better experience of interventionalists and improved features of stents deployed are also expected to boost outcome of endovascular therapy in ICAS. The stent of the future should be more flexible and 
easier to manoeuvre, and the microwire and guiding catheters should be appropriate to support the delivery of the stent system. Drugeluting stents or PTA balloons may be deployed to decrease the rate of persisting ICAS and restenosis.

Another question arises whether endovascular therapy is safe and effective in patients with ICAS-related acute large vessel occlusion. Currently, temporary stent retriever thrombectomy (SRT) and contact aspiration thrombectomy (CAT) are the most frequently applied endovascular therapy strategies in this setting. Several studies have demonstrated comparable efficacy. However, evidence is limited since most data are from small retrospective case series. For successful CAT, an optimal contact with the proximal surface of a thrombus is crucial. However, this contact may be limited in patients with ICAS since ICAS tend to show an irregular shape. A stent retriever touches the full thrombus length and shows a temporary restoration of flow facilitating endogenous thrombolysis. Since large vessel occlusion in ICAS is typically caused by in situ obstruction based on an unstable plaque, there remains a high risk of reocclusion by subsequent platelet activation and thrombus formation. However, an open artery is crucial for improving outcome. Rescue therapy may be discussed after reocclusion. Rescue therapy at present includes switching to another tool (SRT to CAT or vice versa), simultaneous use of both SRT and CAT, infusion of intra-arterial thrombolytics, of intraarterial or intravenous glycoprotein IIb/IIIa inhibitor and transiently or permanently deploying a stent or a stent retriever with or without angioplasty (Fig. 3). Repeated passages of a microwire, a microcatheter and SRT may further damage the unstable plaque and thus provoke more platelet activation or dissection. Intracranial angioplasty with or without permanently deploying a stent retriever bears the risk of occlusion of perforators, vessel injury, resulting in vasospasm, dissection and reocclusion. Infusion of thrombolytics or glycoprotein IIb/IIIa inhibitor elevates the risk of intracranial haemorrhage. Future studies are needed concerning endovascular first-line and rescue therapy in patients with ICAS-related acute large vessel occlusion [134-137].

\section{SURGICAL THERAPY}

Another therapy option to be discussed in patients with ICAS is surgical therapy. Its effectiveness and safety remain unclear. Reperfusion distal to ICAS can be achieved through various bypass surgeries using different donors, recipient arteries and conduit vessels [138].

The landmark international randomised ECIC bypass trial performed in 1977 failed to demonstrate improved outcome after direct bypass versus best medical therapy among patients with recent ischaemic stroke, retinal infarction or TIA attributable to symptomatic extracranial carotid occlusion, distal carotid occlusive disease or ICAS of the middle cerebral artery who were randomly assigned to either best medical therapy (aspirin $1300 \mathrm{mg} /$ day usually divided in four dosages) or to the same regimen with the addition of bypass surgery consisting of joining the superficial temporal artery and the middle cerebral artery. Overall, the study findings did not support surgical therapy in patients with ICAS on a regular basis, especially not in patients with at least 70\% ICAS of the middle cerebral artery. One of the major criticisms that has been raised against the study was the lack of information about haemodynamic status of patients, which were enrolled on the basis of clinical symptoms and angiographic findings only [139-141].

A recent prospective study $(n=112)$ compared EC-IC bypass with/without best medical therapy in patients with symptomatic stenoocclusive disease of the intracranial internal carotid artery or middle cerebral artery. Best medical therapy consisted of adequate control of diabetes mellitus (target HbA1c less than 7\%), blood pressure (below 140/90 $\mathrm{mmHg}$ ), LDL-C (less than $2.6 \mathrm{mmol} / \mathrm{l}$ ) and single antiplatelet therapy (either aspirin $100 \mathrm{mg} /$ day or clopidogrel $75 \mathrm{mg} /$ day). Patients were selected using TCD sonography and cerebral vasodilatory (CVR) assessment using breath-holding index (BHI). Patients with impaired BHI (less than 0.69) were further evaluated with 
acetazolamide-challenge technetium-99m hexamethylpropyleneamine oxime (99mTc HMPAO) SPECT. Bypass surgery was offered to patients with impaired CVR on SPECT. Until 34 months, $13 \%$ vs. $45 \%$ in the surgery vs. in the best medical therapy group developed cerebrovascular ischaemic events. The best medical therapy was, however, suboptimal, lacking a lifestyle modification programme, best lipid-lowering as well as double antithrombotic therapy with aspirin and clopidogrel during the first 90 days after the index event [142].

According to AHA/ASA 2019 guidelines EC/ IC bypass has largely been abandoned as a standard therapy for symptomatic ICAS. However, surgical revascularisation may be considered as a treatment option for patients with recurrent ischaemic stroke despite best medical therapy and pathophysiologically attributed to hypoperfusion with/without bad collaterals, especially if the vascular anatomy is unfavourable for endovascular therapy [66].

\section{CONCLUSION}

Although understanding of ICAS has improved significantly in recent years, further research is warranted for these patients. First, high-quality imaging techniques could further improve diagnostics and assessment of intracranial atherosclerotic plaques. Second, novel, largescale and high-power randomised clinical trials investigating efficacy and safety of best medical therapy including modern treatment such as proprotein convertase subtilisin/kexin type 9 (PSCK9) inhibitors and endovascular therapy are urgently needed. Importantly, careful patient selection for endovascular therapy, related to the underlying pathophysiological mechanism of cerebrovascular ischaemic events, as well as improved endovascular devices could result in better prognosis and outcome. Finally, more attention should be paid to screening and identification of patients with so far asymptomatic ICAS in order to prevent subsequent vascular events.

\section{ACKNOWLEDGEMENTS}

Funding. This research received no specific grant from any funding agency in the public, commercial or not-for-profit sectors.

Authorship. All named authors meet the International Committee of Medical Journal Editors (ICMJE) criteria for authorship for this article, take responsibility for the integrity of the work as a whole, and have given their approval for this version to be published.

Disclosures. Marina Krasteva has received a personal fee for a stroke research fellowship from the Konstantin and Zenovia Katzarovi foundation. Kui Kai Lau has received research sponsorship from Boehringer Ingelheim, Pfizer, Sanofi and Eisai. He has served on the Advisory Board of Boehringer Ingelheim in 2019. Pasquale Mordasini and Anderson Chun On Tsang have nothing to disclose. Mirjam R. Heldner has served on the Advisory Board of Amgen in 2017 and in 2019.

Compliance with Ethics Guidelines. This article is based on previously conducted studies and does not contain any studies with human participants or animals performed by any of the authors.

Open Access. This article is licensed under a Creative Commons Attribution-NonCommercial 4.0 International License, which permits any non-commercial use, sharing, adaptation, distribution and reproduction in any medium or format, as long as you give appropriate credit to the original author(s) and the source, provide a link to the Creative Commons licence, and indicate if changes were made. The images or other third party material in this article are included in the article's Creative Commons licence, unless indicated otherwise in a credit line to the material. If material is not included in the article's Creative Commons licence and your intended use is not permitted by statutory regulation or exceeds the permitted use, you will need to obtain permission directly from the copyright holder.To view 
a copy of this licence, visit http:// creativecommons.org/licenses/by-nc/4.0/.

\section{REFERENCES}

1. Wong LK. Global burden of intracranial atherosclerosis. Int J Stroke. 2006;1:158-9.

2. Qureshi AI, Caplan LR. Intracranial atherosclerosis. Lancet. 2014;383:984-99.

3. White $\mathrm{H}$, Boden-Albala $\mathrm{B}$, Wang $\mathrm{C}$, et al. Ischemic stroke subtype incidence among whites, blacks, and Hispanics: the Northern Manhattan Study. Circulation. 2005;111:1327-31.

4. Sacco RL, Kargman DE, Gu Q, Zamanillo MC. Race-ethnicity and determinants of intracranial atherosclerotic cerebral infarction. The Northern Manhattan Stroke Study. Stroke. 1995;26:14-20.

5. Kasner SE, Chimowitz MI, Lynn MJ, et al. Predictors of ischaemic stroke in the territory of a symptomatic intracranial arterial stenosis. Circulation. 2006;113:555-63.

6. Kern R, Steinke W, Daffertshofer M, Prager R, Hennerici $M$. Stroke recurrences in patients with symptomatic vs asymptomatic middle cerebral artery disease. Neurology. 2005;65:859-64.

7. Mazighi M, Tanasescu R, Ducrocq X, et al. Prospective study of symptomatic atherothrombotic intracranial stenosis: the GESICA study. Neurology. 2006;66:1187-91.

8. Chimowitz MI, Lynn MJ, Howlett-Smith $\mathrm{H}$, et al. Comparison of warfarin and aspirin for symptomatic intracranial arterial stenosis. N Engl J Med. 2005;352:1305-16.

9. Jung JM, Kang DW, Yu KH, et al. Predictors of recurrent stroke in patients with symptomatic intracranial arterial stenosis. Stroke. 2012;43(10): 2785-7.

10. Wityk RJ, Lehman D, Klag M, Coresh J, Ahn H, Litt B. Race and sex differences in the distribution of cerebral atherosclerosis. Stroke. 1996;27(11): 1974-80.

11. Luo J, Wang T, Gao P, Krings T, Jiao L. Endovascular treatment of intracranial atherosclerotic stenosis: current debates and future prospects. Front Neurol. 2018;9:666.

12. Feldmann E, Wilterdink JL, Kosinski A, et al. The Stroke Outcomes and Neuroimaging of Intracranial
Atherosclerosis (SONIA) Trial. Neurology. 2007;68: 2099-106.

13. Brott TG, Howard G, Roubin GS, et al. Long-term results of stenting versus endarterectomy for carotid artery stenosis. N Engl J Med. 2016;374:1021-31.

14. Kumar R, Batchelder A, Saratzis A, et al. Restenosis after carotid interventions and its relationship with recurrent ipsilateral stroke: a systematic review and meta-analysis. Eur J Vasc Endovasc Surg. 2017;53: 766-75.

15. Bonati LH, Gregson J, Dobson J, et al. Restenosis and risk of stroke after stenting or endarterectomy for symptomatic carotid stenosis in the International Carotid Stenting Study (ICSS): secondary analysis of a randomised trial. Lancet Neurol. 2018;17(7):587-96.

16. Mazighi M, Labreuche J, Gongora-Rivera F, Duyckaerts C, Hauw JJ, Amarenco P. Autopsy prevalence of intracranial atherosclerosis in patients with fatal stroke. Stroke. 2008;39:1142-7.

17. Liebeskind DS, Cotsonis GA, Saver JL, et al. Collaterals dramatically alter stroke risk in intracranial atherosclerosis. Ann Neurol. 2011;69(6):963-74.

18. Kasner SE, Chimowitz MI, Lynn MJ, et al. Predictors of ischemic stroke in the territory of a symptomatic intracranial arterial stenosis. Circulation. 2006;113(4):555-63.

19. Gorelick P, Wong KS, Liu L. Epidemiology. In: Kim JS, Caplan LR, Wong KS, editors. Intracranial atherosclerosis: pathophysiology, diagnosis and treatment. Basel: Karger; 2016, vol 40. p. 34-46.

20. Wong KS, Gao S, Chan YL, et al. Mechanisms of acute cerebral infarctions in patients with middle cerebral artery stenosis: a diffusion-weighted imaging and microemboli monitoring study. Ann Neurol. 2002;52(1):74-81.

21. Zhu XJ, Wang W, Liu ZJ. High-resolution magnetic resonance vessel wall imaging for intracranial arterial stenosis. Chin Med J. 2016;129(11):1363-70.

22. Xu WH, Li ML, Gao S, et al. Middle cerebral artery intraplaque hemorrhage: prevalence and clinical relevance. Ann Neurol. 2012;71:195-8.

23. Toussaint JF, La Muraglia GM, Southern JF, et al. Magnetic resonance images lipid, fibrous, calcified, hemorrhagic, and thrombotic components of human atherosclerosis in vivo. Circulation. 1996;94(5):932-8.

24. Chung GH, Kwak HS, Hwang SB, et al. High resolution MR imaging in patients with symptomatic 
middle cerebral artery stenosis. Eur J Radiol. 2012;81(12):4069-74.

25. Zacharatos H, Hassan AE, Qureshi AI. Intravascular ultrasound: principles and cerebrovascular applications. AJNR Am J Neuroradiol. 2010;31(4):586-97.

26. Chen XY, Wong KS, Lam WW, et al. High signal on $\mathrm{T} 1$ sequence of magnetic resonance imaging confirmed to be intraplaque haemorrhage by histology in middle cerebral artery. Int J Stroke. 2014;9:E19.

27. Van Lammeren GW, et al. Atherosclerotic plaque biomarkers: beyond the horizon of the vulnerable plaque. Curr Cardiol Rev. 2011;7:22-7.

28. Sluimer JC, Kolodgie FD, Bijnens AP, et al. Thinwalled microvessels in human coronary atherosclerotic plaques show incomplete endothelial junctions relevance of compromised structural integrity for intraplaque microvascular leakage. J Am Coll Cardiol. 2009;53(17):1517-27.

29. Verhoeven B, Hellings WE, Moll FL, et al. Carotid atherosclerotic plaques in patients with transient ischemic attacks and stroke have unstable characteristics compared with plaques in asymptomatic and amaurosis fugax patients. J Vasc Surg. 2005;42(6):1075-81.

30. Yuan C, Kerwin WS, Ferguson MS, et al. Contrastenhanced high resolution MRI for atherosclerotic carotid artery tissue characterization. J Magn Reson Imaging. 2002;15:62-7.

31. Caplan LR, Wong KS, Gao S, Hennerici MG. Is hypoperfusion an important cause of strokes? If so, how? Cerebrovasc Dis. 2006;21(3):145-53.

32. Kim JS, Nah HW, Park SM, et al. Risk factors and stroke mechanisms in atherosclerotic stroke: intracranial compared with extracranial and anterior compared with posterior circulation disease. Stroke. 2012;43:3313-8.

33. Koo J. The latest information on intracranial atherosclerosis: diagnosis and treatment. Interv Neurol. 2015;4:48-50.

34. Feng X, Chan KL, Lan L, et al. Stroke mechanisms in symptomatic intracranial atherosclerotic disease: classification and clinical implications. Stroke. 2019;50:2692-9.

35. Caplan LR, Hennerici M. Impaired clearance of emboli (washout) is an important link between hypoperfusion, embolism, and ischemic stroke. Arch Neurol. 1998;55(11):1475-82.

36. Baumgartner RW, Mattle HP, Schroth G. Assessment of $>/=50 \%$ and $<50 \%$ intracranial stenoses by transcranial color-coded duplex sonography. Stroke. 1999;30(1):87-92.

37. López-Cancio E, Dorado L, Millán M, et al. The Barcelona-Asymptomatic Intracranial Atherosclerosis (AsIA) study: prevalence and risk factors. Atherosclerosis. 2012;221(1):221-5.

38. Planas-Ballvé A, Crespo AM, Aquilar LM, et al. The Barcelona-Asymptomatic Intracranial Atherosclerotic study: subclinical intracranial atherosclerosis as predictor of long-term vascular events. Atherosclerosis. 2019;282:132-6.

39. Bos D, van der Rijk MJ, Geeraedts TE, et al. Intracranial carotid artery atherosclerosis: prevalence and risk factors in the general population. Stroke. 2012;43(7):1878-84.

40. Nahab F, Cotsonis G, Lynn M, et al. Prevalence and prognosis of coexistent asymptomatic intracranial stenosis. Stroke. 2008;39(3):1039-41.

41. Li Y, Cai Y, Zhao M, Sun J. Risk factors between intracranial-extracranial atherosclerosis and anterior-posterior circulation stroke in ischaemic stroke. Neurol Res. 2017;39:30-5.

42. Banerjee C, Chimowitz MI. Stroke caused by atherosclerosis of the major intracranial arteries. Circ Res. 2017;120:502-13.

43. Lei C, Wu B, Liu M, Chen Y. Risk factors and clinical outcomes associated with intracranial and extracranial atherosclerotic stenoses acute ischaemic stroke. J Stroke Cerebrovasc Dis. 2014;32:112-7.

44. Holmstedt CA, Turan TN, Chimowitz MI. Atherosclerotic intracranial arterial stenosis: risk factors, diagnosis, and treatment. Lancet Neurol. 2013;12(11):1106-14.

45. Chaturvedi S, Turan TN, Lynn MJ, et al. Risk factor status and vascular events in patients with symptomatic intracranial stenosis. Neurology. 2007;69: 2063-8.

46. Lindhorst J, Alexander N, Blignaut J, Rayner B. Differences in hypertension between blacks and whites: an overview. Cardiovasc J Afr. 2007;18(4): 241-7.

47. Alexander RW. Hypertension and the pathogenesis of atherosclerosis. Oxidative stress and the mediation of arterial inflammatory response: a new perspective. Hypertension. 1995;25:155-61.

48. Ritz K, Denswil NP, Stam OC, van Lieshout JJ, Daemen MJ. Cause and mechanisms of intracranial atherosclerosis. Circulation. 2014;130:1407-14. 
49. Sutton-Tyrrell K, Wolfson SK Jr, Kuller LH. Blood pressure treatment slows the progression of carotid stenosis in patients with isolated systolic hypertension. Stroke. 1994;25(1):44-50.

50. Turan TN, Cotsonis G, Lynn MJ, Chaturvedi S, Chimowitz M, Warfarin-Aspirin Symptomatic Intracranial Disease (WASID) Trial Investigators. Relationship between blood pressure and stroke recurrence in patients with intracranial arterial stenosis. Circulation. 2007;115:2969-75.

51. Park JH, Ovbiagele B, Hong KS, Kwon SU. Association of systolic blood pressure with progression of symptomatic intracranial atherosclerotic stenosis. J Stroke. 2017;19(3):304-11.

52. Kwon SU, Hong KS, Kang DW, et al. Efficacy and safety of combination antiplatelet therapies in patients with symptomatic intracranial atherosclerotic stenosis. Stroke. 2011;42:2883-90.

53. Chimowitz MI, Lynn MJ, Derdeyn CP, et al. Stenting versus aggressive medical therapy for intracranial arterial stenosis. N Engl J Med. 2011;365: 993-1003.

54. Turan TN, Nizam A, Lynn M, et al. Relationship between risk factor control and vascular events in the SAMMPRIS trial. Neurology. 2017;88(4):379-85.

55. Amin-Hanjani S, Rose-Finnell L, Richardson D, et al. Vertebrobasilar Flow Evaluation and Risk of Transient Ischaemic Attack and Stroke study (VERiTAS): rationale and design. Int $\mathrm{J}$ Stroke. 2010;5(6): 499-505.

56. Kernan WN, et al. 2014 AHA/ASA guidelines for the prevention of stroke in patients with stroke and transient ischemic attack. A guideline for healthcare professionals from the American Heart Association/ American Stroke Association. Stroke. 2014;45: 2160-236.

57. Mach F, Baigent C, Catapano AL, et al. 2019 ESC/ EAS guidelines for the management of dyslipidaemias: lipid modification to reduce cardiovascular risk: the Task Force for the management of dyslipidaemias of the European Society of Cardiology (ESC) and European Atherosclerosis Society (EAS). Eur Heart J. 2020;41(1):111-88.

58. Bae HJ, Lee J, Park JM, et al. Risk factors of intracranial cerebral atherosclerosis among asymptomatics. Cerebrovasc Dis. 2007;24:355-60.

59. Rincon F, Sacco RL, Kranwinkel G, et al. Incidence and risk factors of intracranial atherosclerotic stroke: the Northern Manhattan Stroke Study. Cerebrovasc Dis. 2009;28:65-71.
60. Katakami N. Mechanism of development of atherosclerosis and cardiovascular disease in diabetes mellitus. J Atheroscler Thromb. 2018;25(1): 27-39.

61. Leung SY, Ng TH, Yuen ST, Lauder IJ, Ho FC. Pattern of cerebral atherosclerosis in Hong Kong Chinese. Severity in intracranial and extracranial vessels. Stroke. 1993;24:779-86.

62. Thomas GN, Lin JW, Lam WW, et al. Increasing severity of cardiovascular risk factors with increasing middle cerebral artery stenotic involvement in type 2 diabetic Chinese patients with asymptomatic cerebrovascular disease. Diabetes Care. 2004;27: 1121-6.

63. Kim YS, Hong JW, Jung WS, et al. Gender differences in risk factors for intracranial cerebral atherosclerosis among asymptomatic subjects. Gend Med. 2011;8:14-22.

64. Matthews DR, Hosker JP, Rudenski AS, Naylor BA, Treacher DF, Turner RC. Homeostasis model assessment: insulin resistance and beta-cell function from fasting plasma glucose and insulin concentrations in man. Diabetologia. 1985;28(7): 412-9.

65. Yaghi S, Furie KL, Viscoli CM, et al. Pioglitazone prevents stroke in patients with a recent transient ischaemic attack or ischaemic stroke: a planned secondary analysis of the IRIS Trial (Insulin Resistance Intervention After Stroke). Circulation. 2018;137(5):455-63.

66. Powers WJ, Rabinstein AA, Ackerson T, et al. Guidelines for the early management of patients with acute ischaemic stroke: 2019 update to the 2018 guidelines for the early management of acute ischaemic stroke: a guideline for healthcare professionals from the American Heart Association/ American Stroke Association. Stroke. 2019;50: e344-418.

67. Ingall TJ, Homer D, Baker HL Jr, Kottke BA, O'Fallon WM, Whisnant JP. Predictors of intracranial carotid artery atherosclerosis. Duration of cigarette smoking and hypertension are more powerful than serum lipid levels. Arch Neurol. 1991;48:687-91.

68. Heyden S, Heyman A, Goree JA. Nonembolic occlusion of the middle cerebral and carotid arteries-a comparison of predisposing factors. Stroke. 1970;1:363-9.

69. Wang Y, Meng R, Liu G, et al. Intracranial atherosclerotic disease. Neurobiol Dis. 2019;124: 118-32.

70. Barth JD, Arntzenius AC. Progression and regression of atherosclerosis, what roles for LDL-cholesterol 
and HDL-cholesterol: a perspective. Eur Heart J. 1991;12(8):952-7.

71. Weber G. Delayed experimental atherosclerotic involvement of cerebral arteries in monkeys and rabbits. Pathol Res Pract. 1985;180:353-5.

72. Inzitari D, Hachinski VC, Taylor DW, Barnett HJ. Racial differences in the anterior circulation in cerebrovascular disease: how much can be explained by risk factors? Arch Neurol. 1990;47: 1080-4.

73. Park JH, Hong KS, Lee EJ, Lee J, Kim DE. High levels of apolipoprotein B/AI ratio are associated with intracranial atherosclerotic stenosis. Stroke. 2011;42(11):3040-6.

74. Turan TN, Makki AA, Tsappidi S, et al. Risk factors associated with severity and location of intracranial arterial stenosis. Stroke. 2010;41(8):1636-40.

75. Amarenco P, Bogousslavsky J, Callahan A 3rd, et al. High-dose atorvastatin after stroke or transient ischaemic attack. N Engl J Med. 2006;10:549-59.

76. Amarenco P, Kim JS, Labreuche J, et al. A comparison of two LDL cholesterol targets after ischemic stroke. N Engl J Med. 2020;382:9-19.

77. Kernan WN, Inzucchi SE, Sawan C, Macko RF, Furie KL. Obesity: a stubbornly obvious target for stroke prevention. Stroke. 2013;44:278-86.

78. Gallanagh S, Quinn TJ, Alexander J, Walters MR. Physical activity in the prevention and treatment of stroke. ISRN Neurol. 2011;2011:953818.

79. Turan TN, Kasab SA, Nizam A, et al. Type and duration of exercise in the SAMMPRIS trial. Neurologist. 2019;24(1):10-2.

80. Piercy KL, Troiano RP, Ballard RM, et al. The physical activity guidelines for Americans. JAMA. 2018;320(19):2020-8.

81. Ambrose JA, Barua RS. The pathophysiology of cigarette smoking and cardiovascular disease: an update. J Am Coll Cardiol. 2004;43(10):1731-7.

82. Ji R, Pan Y, Yan H, et al. Current smoking is associated with extracranial carotid atherosclerotic stenosis but not with intracranial large artery disease. BMC Neurol. 2017;17(1):120.

83. Kim DE, Lee KB, Jang IM, Roh H, Ahn MY, Lee J. Associations of cigarette smoking with intracranial atherosclerosis in the patients with acute ischaemic stroke. Clin Neurol Neurosurg. 2012;114:1243-7.

84. Miyazawa N, Akiyama I, Yamagata Z. Analysis of incidence and risk factors for progression in patients with intracranial steno-occlusive lesions by serial magnetic resonance angiography. Clin Neurol Neurosurg. 2007;109:680-5.

85. Chen $\mathrm{H}$, Hong $\mathrm{H}$, Xing $\mathrm{S}$, et al. Intracranial versus extracranial symptomatic carotid atherosclerosis in Chinese patients: risk factors, stroke mechanisms, and long-term prognosis. J Stroke Cerebrovasc Dis. 2015;24:2632-9.

86. Turan TN, Al Kasab S, Nizam A, et al. Relationship between risk factor control and compliance with a lifestyle modification program in the Stenting Aggressive Medical Management for Prevention of Recurrent Stroke in Intracranial Stenosis Trial. J Stroke Cerebrovasc Dis. 2018;27(3):801-5.

87. Wang JC, Bennett M. Aging and atherosclerosis. Circ Res. 2012;111:245-59.

88. Kim JS, Bonovich D. Research on intracranial atherosclerosis from the east and west: why are the results different? J Stroke. 2014;16(3):105-13.

89. Forouhi NG, Sattar N. CVD risk factors and ethnicity-a homogeneous relationship? Atheroscler Suppl. 2006;7:11-9.

90. Chandalia M, Abate N, Garg A, Stray-Gundersen J, Grundy SM. Relationship between generalized and upper body obesity to insulin resistance in Asian Indian men. J Clin Endocrinol Metab. 1999;84: 2329-35.

91. Kuller L, Reisler DM. An explanation for variations in distribution of stroke and atherosclerotic heart disease among populations and racial groups. Am J Epidemiol. 1997;93:1-9.

92. Kim SJ, Moon GJ, Bang OY. Biomarkers for stroke. J Stroke. 2013;15:27-37.

93. Liao X, Zhang T, Li B, et al. Rare RNF213 variants and the risk of intracranial artery stenosis/occlusion disease in Chinese population: a case-control study. BMC Med Genet. 2019;20(1):55.

94. Genton E, Barnett HJ, Fields WS, Gent M, Hoak JC. Cerebral ischemia: the role of thrombosis and of antithrombotic therapy. Study group on antithrombotic therapy. Stroke. 1977;8:150-75.

95. Alberts MJ, Bergman DL, Molner E, Jovanovic BD, Ushiwata I, Teruya J. Antiplatelet effect of aspirin in patients with cerebrovascular disease. Stroke. 2004;35:175-8.

96. Helgason CM, Bolin KM, Hoff JA, et al. Development of aspirin resistance in persons with previous ischaemic stroke. Stroke. 1994;25:2331-6. 
97. Ratnatunga CP, Edmondson SF, Rees GM, Kovacs IB. High-dose aspirin inhibits shear-induced platelet reaction involving thrombin generation. Circulation. 1992;85:1077-82.

98. Ridker PM, Cushman M, Stampfer MJ, Tracy RP, Hennekens $\mathrm{CH}$. Inflammation, aspirin, and the risk of cardiovascular disease in apparently healthy men. N Engl J Med. 1997;336:973-9.

99. Kharbanda RK, Walton B, Allen M, et al. Prevention of inflammation-induced endothelial dysfunction: a novel vasculo-protective action of aspirin. Circulation. 2002;105:2600-4.

100. Khan A, Kasner SE, Lynn MJ, Chimowitz MI, Warfarin Aspirin Symptomatic Intracranial Disease (WASID) Trial Investigators. Risk factors and outcome of patients with symptomatic intracranial stenosis presenting with lacunar stroke. Stroke. 2012;43(5):1230-3.

101. Kasner SE, Lynn MJ, Chimowitz MI, et al. Warfarin vs aspirin for symptomatic intracranial stenosis: subgroup analyses from WASID. Neurology. 2006;67(7):1275-8.

102. Lip GYH, Keshishian A, Li X, et al. Effectiveness and safety of oral anticoagulants among nonvalvular atrial fibrillation patients. Stroke. 2018;49:2933-44.

103. Patel MR, Mahaffey KW, Garg J, et al. Rivaroxaban versus warfarin in nonvalvular atrial fibrillation. N Engl J Med. 2011;365(10):883-91.

104. Patel P, Pandya J, Goldberg M. NOACs vs. warfarin for stroke prevention in nonvalvular atrial fibrillation. Cureus. 2017;9:1395.

105. Xue Z, Zhang H. Non-vitamin K antagonist oral anticoagulants versus warfarin in Asians with atrial fibrillation: meta-analysis of randomized trials and real-world studies. Stroke. 2019;50:2819-28.

106. Wong KS, Chen $\mathrm{C}, \mathrm{Fu} \mathrm{J}$, et al. Clopidogrel plus aspirin versus aspirin alone for reducing embolisation in patients with acute symptomatic cerebral or carotid artery stenosis (CLAIR study): a randomised, open-label, blinded-endpoint trial. Lancet Neurol. 2010;9:489-97.

107. Wang Y, Wang Y, Zhao X, et al. Clopidogrel with aspirin in acute minor stroke or transient ischemic attack. N Engl J Med. 2013;369(1):11-9.

108. Liu L, Wong KS, Leng X, et al. Dual antiplatelet therapy in stroke and ICAS: subgroup analysis of CHANCE. Neurology. 2015;85(13):1154-62.

109. Zaidat OO, Fitzsimmons BF, Woodward BK, et al. Effect of a balloon-expandable intracranial stent vs medical therapy on risk of stroke in patients with symptomatic intracranial stenosis: the VISSIT randomized clinical trial. JAMA. 2015;313:1240-8.

110. Kwon SU, Cho YJ, Koo JS, et al. Cilostazol prevents the progression of the symptomatic intracranial arterial stenosis: the multicenter double-blind placebo-controlled trial of cilostazol in symptomatic intracranial arterial stenosis. Stroke. 2005;36:782-6.

111. Johnston SC, Amarenco P, Albers GW, et al. Ticagrelor versus aspirin in acute stroke or transient ischaemic attack. N Engl J Med. 2016;375:35-43.

112. Amarenco P, Albers GW, Denison H, et al. Efficacy and safety of ticagrelor versus aspirin in acute stroke or transient ischaemic attack of atherosclerotic origin: a subgroup analysis of SOCRATES, a randomised, double-blind controlled trial. Lancet Neurol. 2017;16:301-10.

113. Ogawa A, Toyoda K, Kitagawa K, et al. Comparison of prasugrel and clopidogrel in patients with noncardioembolic ischaemic stroke: a phase 3, randomised, non-inferiority trial (PRASTRO-I). Lancet Neurol. 2019;18(3):238-47.

114. Fiorella D. Endovascular treatment of intracranial stenosis. World Neurosurg. 2011;76(6):66-70.

115. Sundt TM, Smith HC, Campbell JK, et al. Transluminal angioplasty for basilar artery stenosis. Mayo Clin Proc. 1980;55:673-80.

116. Connors JJ, Wojak JC. Percutaneous transluminal angioplasty for intracranial atherosclerotic lesions: evolution of technique and short-term results. J Neurosurg. 1999;91:415-23.

117. Feldman RL, Trigg L, Gaudier J, et al. Use of coronary Palmaz-Schatz stent in the percutaneous treatment of an intracranial carotid artery stenosis. Cathet Cardiovasc Diagn. 1996;38:316-9.

118. Rasmussen PA, Perl J, Barr JD, et al. Stent-assisted angioplasty of intracranial vertebrobasilar atherosclerosis: an initial experience. J Neurosurg. 2000;92:771-8.

119. Marks MP, Wojak JC, Al-Ali F, et al. Angioplasty for symptomatic intracranial stenosis: clinical outcome. Stroke. 2006;37:1016-20.

120. SSYLVIA Study Investigators. Stenting of symptomatic atherosclerotic lesions in the vertebral or intracranial arteries (SSYLVIA): study results. Stroke. 2004;35:1388-92.

121. Derdeyn CP, Chimowitz MI, Lynn MJ, et al. Aggressive medical treatment with or without stenting in high-risk patients with intracranial artery stenosis (SAMMPRIS): the final results of a randomised trial. Lancet. 2014;383:331-41. 
122. Bose A, Hartmann M, Henkes $H$, et al. A novel, selfexpanding, nitinol stent in medically refractory intracranial atherosclerotic stenoses: the Wingspan study. Stroke. 2007;38:1531-7.

123. Amin-Hanjani S, Stapleton CJ, Du X, et al. Hypoperfusion symptoms poorly predict hemodynamic compromise and stroke risk in vertebrobasilar disease. Stroke. 2019;50(2):495-7.

124. Lutsep HL, Lynn MJ, Cotsonis GA, et al. Does SAMMPRIS support stenting over medical therapy for subpopulations of patients with intracranial arterial stenosis? Stroke. 2015;46(11):3282-4.

125. Fiorella D, Derdeyn CP, Lynn MJ, et al. Detailed analysis of periprocedural strokes in patients undergoing intracranial stenting in stenting and aggressive medical management for preventing recurrent stroke in intracranial stenosis (SAMMPRIS). Stroke. 2012;43:2682-8.

126. Abou-Chebl A, Steinmetz H. Critique of "Stenting versus aggressive medical therapy for intracranial arterial stenosis" by Chimowitz et al in the New England Journal of Medicine. Stroke. 2012;43: 616-20.

127. Gröschel K, Schnaudigel S, Pilgram SM, Wasser K, Kastrup A. A systematic review on outcome after stenting for intracranial atherosclerosis. Stroke. 2009;40:e340.

128. Markus HS, Larsson SC, Kuker W, et al. Stenting for symptomatic vertebral artery stenosis. Neurology. 2017;89:1229-36.

129. Compter A, van der Worp HB, Schonewille WJ, et al. Stenting versus medical treatment in patients with symptomatic vertebral artery stenosis: a randomised open-label phase 2 trial. Lancet Neurol. 2015;14(6): 606-14.

130. Alexander MJ, Zauner A, Chaloupka JC, et al. WEAVE trial: final results in 152 on-label patients. Stroke. 2019;50(4):889-94.

131. Gao P, Zhao Z, Wang D, et al. China Angioplasty and Stenting for Symptomatic Intracranial Severe Stenosis (CASSISS): a new, prospective, multicenter, randomized controlled trial in China. Interv Neuroradiol. 2015;2:196-204.

132. Mori T, Fukuoka M, Kazita K, Mori K. Follow-up study after intracranial percutaneous transluminal cerebral balloon angioplasty. AJNR Am J Neuroradiol. 1998;19(8):1525-33.

133. Miao Z, Song L, Liebeskind DS, et al. Outcomes of tailored angioplasty and/or stenting for symptomatic intracranial atherosclerosis: a prospective cohort study after SAMMPRIS. J Neurointerv Surg. 2015;7(5):331-5.

134. Kang DH, Yoon W. Current opinion on endovascular therapy for emergent large vessel occlusion due to underlying intracranial atherosclerotic stenosis. Korean J Radiol. 2019;20:739-48.

135. Park H, Baek JH, Kim BM. Endovascular treatment of acute stroke due to intracranial atherosclerotic stenosis-related large vessel occlusion. Front Neurol. 2019;2(10):308.

136. Lee JS, Hong JM, Lee KS, et al. Endovascular therapy of cerebral arterial occlusions: intracranial atherosclerosis versus embolism. J Stroke Cerebrovasc Dis. 2015;24:2074-80.

137. Kim BM. Causes and solutions of endovascular treatment failure. J Stroke. 2017;19:131-42.

138. Kawashima M, Rhoton AL Jr, Tanriover N, Ulm AJ, Yasuda A, Fujii K. Microsurgical anatomy of cerebral revascularization. Part I: anterior circulation. J Neurosurg. 2005;102:116-31.

139. EC/IC Bypass Study Group. Failure of extracranialintracranial arterial bypass to reduce the risk of ischaemic stroke. Results of an international randomized trial. N Engl J Med. 1985;313:1191-200.

140. Awad IA, Spetzler RF. Extracranial-intracranial bypass surgery: a critical analysis in light of the international cooperative study. Neurosurgery. 1986;19:655-64.

141. Ausman JI, Diaz FG. Critique of the extracranialintracranial bypass study. Surg Neurol. 1986;26(3): 218-21.

142. Low SW, Teo K, Lwin S, et al. Improvement in cerebral hemodynamic parameters and outcomes after superficial temporal artery-middle cerebral artery bypass in patients with severe steno occlusive disease of the intracranial internal carotid or middle cerebral arteries. J Neurosurg. 2015;123(3):662-9. 